\title{
Neuronal Connections and the Function of the Corpora Pedunculata in the Brain of the American Cockroach, Periplaneta americana (L.) ${ }^{1}$
}

\author{
MITCHELL J. WEISS 2 \\ Department of Zoology, The University of Michigan, Ann Arbor \\ Michigan, 48104
}

\begin{abstract}
The fiber constituents and connections of the calyces - the input-receiving regions - of the corpora pedunculata ("mushroom bodies") were studied in reduced silver preparations from the American cockroach, Periplaneta americana (L.). In the outer synaptic layer of the calyces five fiber classes were distinguished, the first three of which arise outside the mushroom body. (1) Four highly similar neurons with somata near the optic lobe branch into different parts of the ipsilateral protocerebrum, including both calyces. Their fibers are highly constant in arrangement and position and contain small nucleus-like bodies. (2) The tractus olfactorio-globularis (sensu lato) emits fiber groups which course along the calycal walls as "calycal tracts" before ultimately dissipating into the synaptic layer. Variability within these tracts is described. (3) Fibers of undetermined origin outside the mushroom body radiate from the calycal center outwards through the synaptic layer. (4) From the inner calycal layer of neurites belonging to intrinsic mushroom-body neurons, perpendicular collaterals enter the synaptic layer. (5) Intrinsic-neuron somata near the calycal rim emit fibers which course tangentially within the synaptic layer from calycal rim to center. These fibers form a special peripheral zone in the pedunculus.

The predominant presumably afferent calycal fiber class is that derived from the tractus olfactorio-globularis. No evidence was found for tracts from optic lobe to calyces. On this basis, and in light of the experimental and comparative anatomical literature, it is suggested that the corpora pedunculata of $P$. americana and other pterygotes are fundamentally second-order antennal sensory processing centers.

Conflicting observations in earlier reports are critically discussed.
\end{abstract}

Few structures within the nervous systems of invertebrates have attracted as long-lasting an interest as have the corpora pedunculaia or "mushroom bodies" of the insect brain. What biological role do these often strikingly prominent centers play? This question has been asked repeatedly since Dujardin (1850) discovered the corpora pedunculata in a range of insects and related their degree of development to the level of "intelligence" (for extensive bibliographies see Hanström, '28; Horridge, '65; Gouin, '65). Yet a convincing answer has remained elusive. The question will be approached here through structural examination of the kinds of input the corpora pedunculata receive.

The principal inputs of the corpora pedunculata are believed to arrive through tracts to their calyces (fig. 1): Maynard's work ('56, '67) supplies the strongest electrophysiological support for this view. Although numerous papers describe calycal fiber connections in various insects (see above bibliographies), for no one species is a sufficiently full, adequately documented account available. This situation stems from limitations in the techniques used. Most workers have used common dyes such as haematoxylin, but because these ordinarily show individual nerve fibers poorly their employment usually leads to erroneous or at best unconvincing asser-

\footnotetext{
1 Based on portions of a dissertation submitted to the Department of Zoology, The University of Michigan, in partial fulfilment of the requirements for the degree of partial fulfilment of the requiren
Doctor of Philosophy (Weiss, "70).

2 Present address: Department of Zoology, University of Iowa, Iowa City, Iowa 52242.
} 
tions. On the other hand, two of the three major types of neurological technique capable of showing nerve fibers clearly, Golgi impregnation and intra vitam methylene blue, display only an unknown and possibly biased proportion of neurons present in a preparation and often only neuronal fragments, so that the extent to which the information they provide is either representative or complete remains uncertain. The best hope for obtaining a convincing cataloging of at least all major calycal connections, with knowledge of relative fiber numbers, lies with the "total stain-

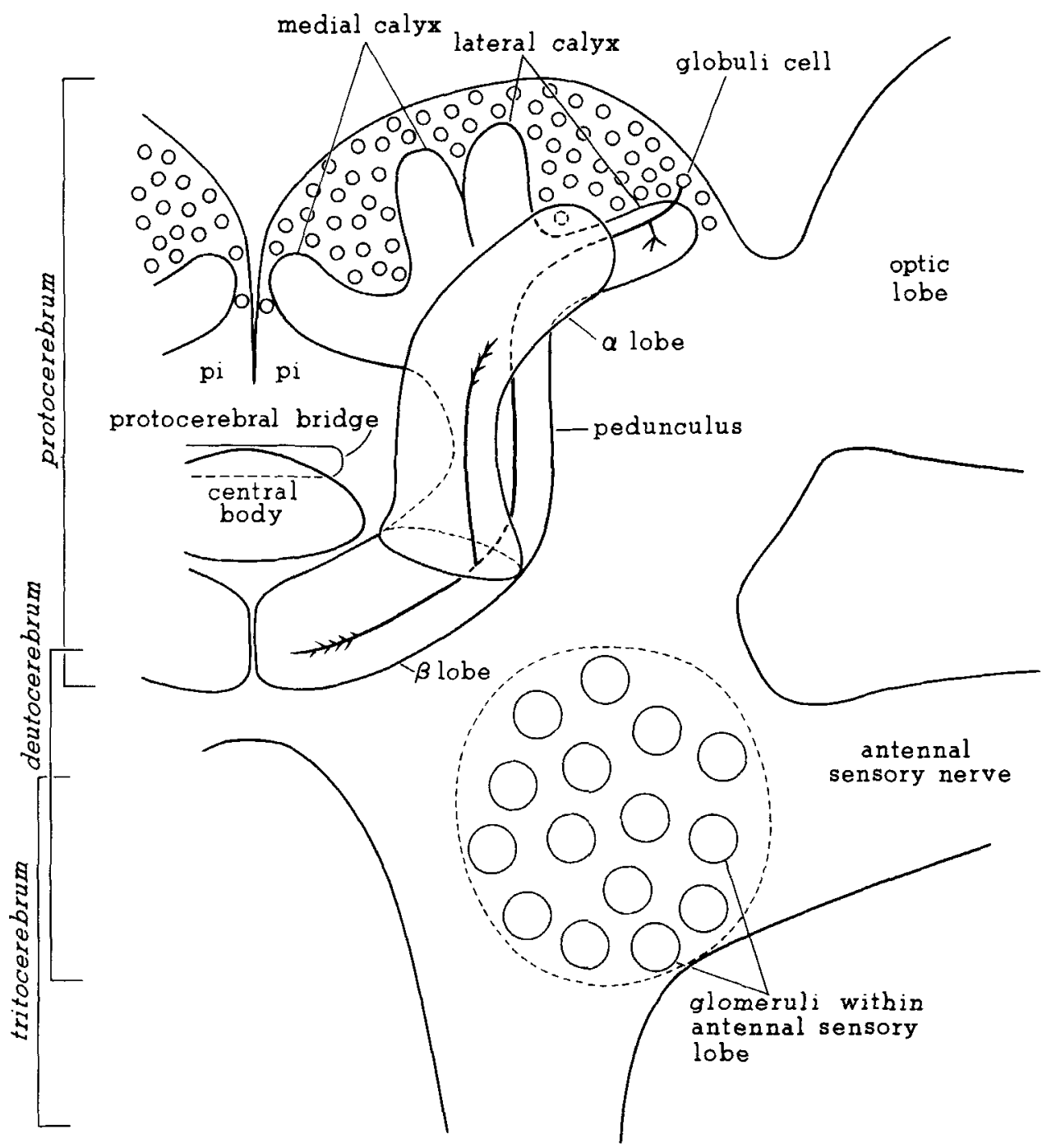

Fig. 1 Diagram of left half of the brain of adult male $P$, americana, viewed from the front. Most nerves are omitted. Proto-, deuto-, tritocerebrum, the three traditionally recognized "divisions" of the brain; protocerebral bridge, central body, special neuropilar formations of the protocerebrum; pi, pars intercerebralis, a medial zone of the protocerebrum; medial calyx, lateral calyx, pedunculus, $\alpha$ lobe, $\beta$ lobe, the different neuropilar divisions of the corpus pedunculatum. Note large antennal sensory nerve and correspondingly large antennal sensory lobe of the deutocerebrum. Within the corpus pedunculatum the basic arrangement of a typical globuli cell is illustrated; the number and pattern of its collaterals are shown highly schematically. Conduction within the globuli cells is believed (see Maynard, '56, '67) to extend from the calyces through the pedunculus and into the $\alpha$ and $\beta$ lobes, whose connections presumably are essentially efferent. (Details of globuli cell combined from various published sources.) 
ing" method of reduced silver impregnation.

A thorough description of calycal connections from reduced silver preparations has never been published. Vowles ('55) offers a list of connections in a bee and an ant but does not provide detailed documentation. Pearson's ('71) admirable study of lepidopteran corpora pedunculata involved reduced silver as well as Golgi-silver preparations; her treatment of the calycal connections, however, relies primarily on the latter.

In this study, based on reduced silver preparations from the American cockroach, Periplaneta americana (L.), I have attempted to elucidate the calycal fiber connections by distinguishing all visible fiber classes within the calyces and determining as fully as possible their courses and origins inside or outside the corpus pedunculatum. The calyces of $P$. americana, while particularly large, are in basic form and arrangement typical of many pterygotes. The study has been made possible by development of a reduced silver procedure (Weiss, '72a) which permits fine ramifications of entering fibers and tracts to be visualized: in the best impregnations fibers of 0.2 - to $0.3-\mu$ diameter are visible within the calycal neuropile. The results provide evidence that the calyces of $P$. americana serve primarily as second-order antennal centers and suggest that in this insect and others the chief function of the corpus pedunculatum may profitably be viewed as the processing of antennal sensory information.

An abstract of this study has previously appeared (Weiss, '71).

\section{MATERIALS AND METHODS}

Specimens of Periplaneta americana were taken from a laboratory culture kindly furnished originally by Dr. Louis $M$. Roth. The brains of 41 adult males were prepared according to an improved version (Weiss, '72a) of Blest's collidine modification of Holmes' reduced silver impregnation method, with occasional technical variations which proved either unessential or unsuccessful. The procedure includes fixation in Bodian's ('37) fixative No. 2 and paraffin embedding. In 24 cases the entire brain was sectioned serially, ordinarily at $10 \mu$. In 17 cases $10-\mu$ serial sections were prepared of half or slightly more of the brain (these originally served as "test" slides). All three major sectioning planes were represented. While many preparations proved useful, only a few exhibit impregnations suitable for the more demanding observations. These include whole brains sectioned transversely and frontally (see terminology below). A few similarly stained preparations from both sexes of Periplaneta $s p{ }^{3}$ have been available for reference; these include a beautifully impregnated sagittal series through the complete brain. Unless otherwise indicated, the observations deal exclusively with adult male $P$. americana.

The terms frontal and transverse will refer respectively to section planes approximately parallel to (1) the surface of the protocerebrum (see fig. 1) facing the frons and (2) the plane dividing the brain into dorsal and ventral halves. Usage of terms such as dorsal and anterior assumes the head to be held in a generally vertical position. The apex of the protocerebral lobe is considered dorsal, the protocerebral surface facing the frons, anterior, and so forth.

Unless otherwise noted, serial tracing of fiber bundles and tracts has been carried out under $1000 \times$ magnification, with careful attention to establishing continuity between fiber groups in adjacent sections. Most of the photomicrographs necessarily show objects at lower magnification than that used for the original observations.

\section{OBSERVATIONS}

The microscopic anatomy of the corpora pedunculata and their fiber connections with other regions have been examined in various genera of cockroaches (Dictyoptera: Blattaria) (Flögel, 1876, ${ }^{4}$ 1878; New-

\footnotetext{
${ }^{3}$ Obtained commercially several years ago under the name "P. americana" but later identified in retrospect as almost certainly P. fuliginosa.

4 On 21 September 1876, in Hamburg, Flögel delivered before one of the sections of the Geselischaft deutscher Naturforscher und Aerzte a remarkable lecture, filled with detail, concerning the inner structure of the brain of insects and other arthropods as visible in microtome sections, thu formally inaugurating the modern era of the study of the insect brain. The published text (Flögel, 1876) has remained in obscurity, only Holste ('23), of later authors, even alluding vaguely to its existence. Many specific findings on insect corpora pedunculata, as well as the introduction of various standard names for structures within the insect brain ( $B$ alhen, Centralkörper, etc.), date not from Flögel's wellknown study of 1878 but from this 1876 publication.
} 
ton, 1879; Haller, '05; Holmgren, '09; Bretschneider, '13a,b, '14; Hanström, '28, '40; Sánchez y Sánchez, '33; Jawlowski, '48, '53; Day, '50; Lhoste and Roche, '56; Arnold, '60; Drescher, '60; Barbier, '61; Willey, '61, p. 235; Satija and Singla, '67; Prigent, '68; Brousse-Gaury, '68, '71). Information is also available concerning related aspects of cockroach mushroom bodies: growth and development (Panov, '57; Neder, '59; Khan, '62; Khan and Fraser, '62; Malzacher, '68; Levi-Montalcini and Chen, '69, fig. 1; Chen and Levi-Montalcini, '70; Weiss, '72b; see also Ratzerdorfer, '52), histochemistry (Shao and Dixon, '64, fig. 1; Frontali and Norberg, '66; Frontali, '68, '71a,b; Mancini and Frontali, 70; Frontali, Piazza and Scopelliti, '71; Hess, '72; Frontali and Pierantoni, '73), and ultrastructural anatomy and cytochemistry (Arnold, '64; Mancini and Frontali, '67, '68, '70; Frontali and Mancini, '70; Frontali, '71a,b; Weiss, '71; fig. 15 in Maynard, '67).

Beginning with Flögel (1876, 1878), nearly all authors have attributed the same basic construction (fig. 1) to the corpus pedunculatum of different cockroaches. Dorsally there are two calyces, sometimes but not invariably truly concave, which are overlain by numerous globuli cell somata. The calyces give rise ventrally to a stalklike pedunculus which bifurcates at its distal (ventral) end into two elongate lobes (named here following Vowles, '55). The medial $\beta$ lobe extends to the midline, while the dorsal $\alpha$ lobe ascends for some distance near the front surface of the brain. Haller's ('05) divergent account clearly resulted from misunderstanding of both Newton's (1879) work and his own preparations (note the self-contradictory figure labels), while Sánchez y Sánchez's ('33) incorrect interpretations seem to have originated largely in Haller's account. It is clear from the fiber arrangement of the typical globuli cell shown in figure 1 that the gross form of the mushroom body reflects the branching pattern of its globuli cells. These may be termed intrinsic cells and their fibers intrinsic fibers of the mushroom body, while fibers entering the mushroom body from outside, with cell bodies elsewhere in the nervous system, may be termed extrinsic. Periplaneta americana (e.g., Hanström, '28, '40; Jawlowski, '48) is one of those cockroaches with large, deeply concave calyces.

My observations reconfirm this basic plan of construction in $P$. americana (figs. $5,6,13,20$ ), although it remains possible that a small proportion of intrinsic fibers may leave the $\alpha$ or $\beta$ lobe, for example in the manner Drescher ('60) describes. In one specimen a striking departure from the usual conditions was found, in that the two $\beta$ lobes were medially fused. Drescher ('60) found such fusion in about $2 \%$ of his specimens of $P$. americana, and Haller ('05) saw it in Blatta orientalis.

As Flögel (1876) originally reported in Blatta orientalis and Hanström ('28) and others have since confirmed for $P$. americana, the calycal walls in this species comprise two distinct layers (fig. 7). That adjoining the calycal concavity, though variable in width, is always the thinner, and will be designated zona interna in recognition of its internal position. It is believed to consist (e.g., Hanström, '28) of globuli cell neurites which extend tangentially through it in to the pedunculus, meanwhile emitting dendritic processes into the subjacent layer. The latter, here termed zona externa in accordance with its position, is believed to consist (e.g., Hanström, '28) of intermingled terminal ramifications of globuli cell dendrites and afferent extrinsic fibers, and thus is regarded as the synaptic layer. Where the vertical walls of both calyces are in apposition, their zonae externae lie in contact (fig. 41) and contrary to a previous report (Hanström, '40) appear continuous in some regions. In such places an extrinsic fiber has occasionally seemed to pass between them.

In the silver preparations studied, the zona interna is characterized by the presence of numerous very narrow fibers oriented tangentially to the calycal wall. These commonly have been seen emanating, typically in small bundles, and in only certain areas, from the layer of globuli cell somata adjacent to the internal calycal surface (fig. 7). In addition, small bundles of processes from within the zona interna pass perpendicularly into the zona externa (fig. 8). Although they have been seen most clearly in the ventral wall of the medial calyx, they nearly certainly occur also in the ventral wall of the lateral calyx and the apposed vertical walls of both calyces. Thus 
they are widely distributed over the calyces, but whether their distribution is uniform remains undetermined.

The zona interna of each calyx resembles a misshapen funnel which gives rise to a solid stem. Within each zona interna the fibers converge ventrally to leave the calyx as one of the two "roots" of the pedunculus (figs. 13, 40); further ventrad, these "roots" shortly unite to produce the pedunculus proper. There has been much inconsistency among different authors in denoting these "peduncular roots," some even calling each of them a "pedunculus." I shall refer to them as the two peduncular columns.

My observations have furnished no convincing evidence for the normal presence of extrinsic nerve fibers within the zona interna.

The zona externa appears very different in texture from the zona interna. It is characterized by a matrix of fairly homogeneous appearance, typically moderately stained, through which course distinctly impregnated nerve fibers of widely varied diameters. Some of these plunge directly into its midst from outside it; others, either singly or in the form of well-defined bundles or tracts, first travel along its external margin (in which $I$ include, throughout this paper, the portion of the calycal margin at the region of calycal apposition), sometimes emitting branches or bifurcating during their course, and finally become lost in the interior of the layer. Within the zona externa I have distinguished several nerve fiber classes, some representing extrinsic and others intrinsic fibers. These classes will now be treated in turn, including, where known, their origin and specific topographical arrangement within or beyond the corpus pedunculatum.

\section{Quartet neurons}

On each side of the brain is a group of four similar neurons which connect the calyces with other brain regions. These neurons will be designated quartet cells.

The quartet cells were first discovered and examined in detail in several preparations from Periplaneta $s p$. In serial sections cut in the three major planes, it proved possible, starting at the calyces, to follow the various groups of branches of these neurons until, inevitably, one group led to the cell bodies. Continued work established the constancy of the number and position of cell bodies and of the position and arrangement of the groups of major fiber branches. These neurons have subsequently been studied in P. americana. In each of six hemispheres (four frontally, one transversely, and one sagittally sectioned) they have been carefully traced from the somata as far distad as possible along all observed branches; in addition, less critical observations at $400 \times$ have been made on most or all major branches in each of over a dozen other hemispheres. This work on $P$. americana has confirmed the existence of the same bundles of major fiber branches established earlier in Periplaneta $s p$. Figure 2 indicates the numbers assigned for purposes of discussion to the various fiber regions of these neurons in $P$. americana.

The four somata of the quartet cells of one side (fig. 9) lie adjacent to one another in the protocerebral cortex, at the point where the postero-ventral surface of the optic lobe (see fig. 1) joins the protocerebrum. The cell bodies are large: measurements of greatest diameter in a plane transverse to the axis of the stem process for two sets of cells from different brains gave a range of $30 \mu$ to $43 \mu$, with a mean of $35 \mu .5$ Each nucleus, usually slightly ovoidal in section, contains a single prominent nucleolus which often appears pitch black in the silver preparations (fig. 10).

The stem processes of these unipolar somata are oriented approximately in the transverse plane and give rise to thick fibers (figs. 11, 37) which enter the posterior protocerebral neuropile in this plane at an angle of usually more than $45^{\circ}$ towards the midline (figs. 10,12). The fibers immediately turn more anteriad and somewhat dorsad and travel dorso-medio-anteriad toward their main branching region. En route, each of the four fibers gives rise to branch 2 (fig. 13), which extends pos-

\footnotetext{
${ }^{5}$ All measurements given should be recognized as applying strictly to preserved brains processed as indicated above. The values for large distances or sizable structures may be expected to correspond roughly to those obtaining in the living animal (erring on the low side), but in the case of individual nerve fibers, shrinkage can be so appreciable (as indicated both by the presence of shrinkage spaces surrounding individual fibers and by some comparisons with electron micrographs) that the diameter in the silver preparations may represent half or even less of the actual diameter in the living tissue.
} 
tero-dorsad for some tens of microns and then may fork. The further course of these branches is unknown.

Having given rise to branch 2, each main fiber continues to the most prominent branching region of the neuron (fig. 14). This region, whose characteristic appearance usually renders it easily identifiable
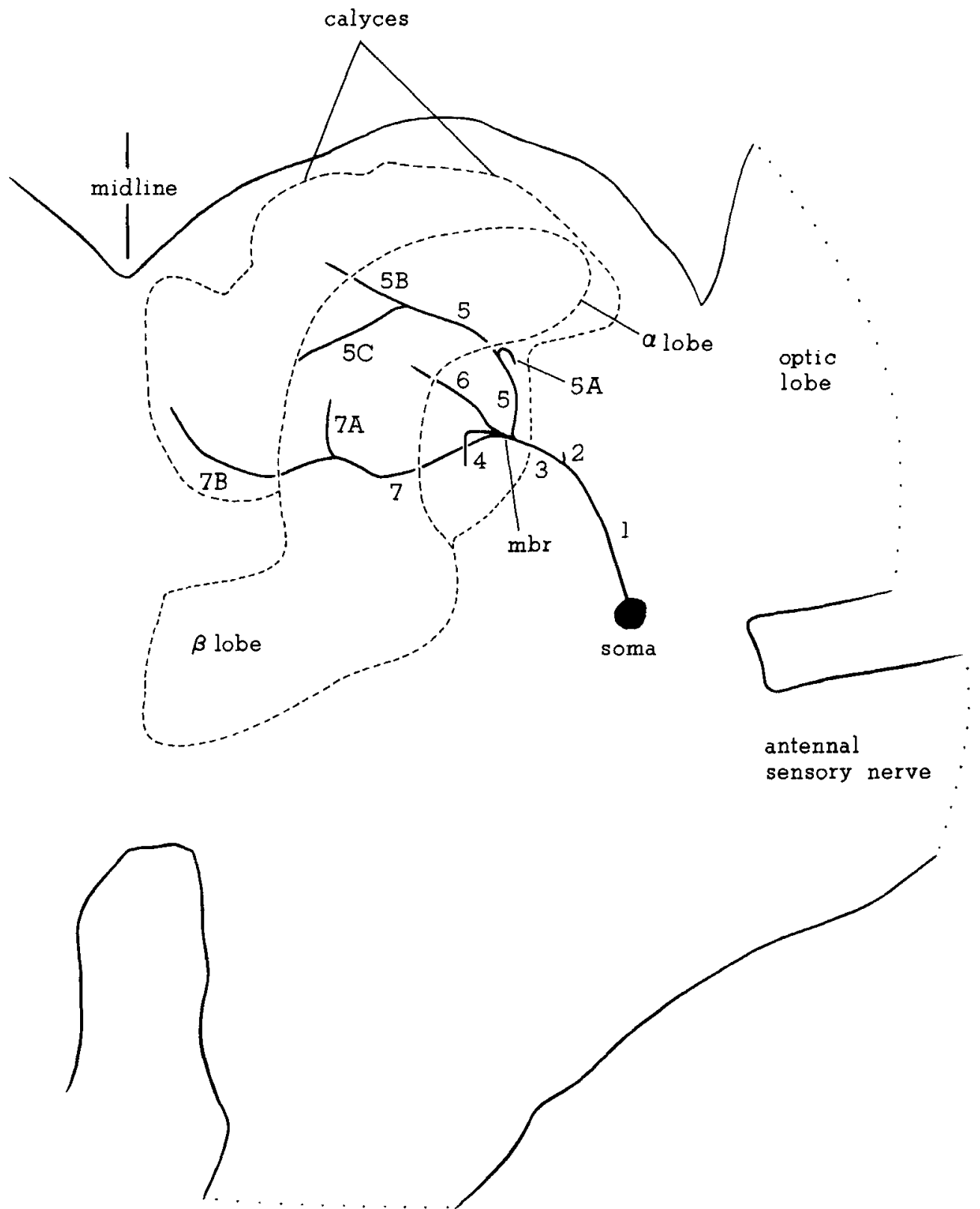

Fig. 2 Schematized representation of the branching pattern of the quartet neuron fiber bundles, shown as though projected onto a frontal plane and viewed from the front. Dorsal is upwards. The outer boundaries of the brain surface and of parts of the corpus pedunculatum are also shown. The numbers indicate various fiber regions; $\mathrm{mbr}$, main branching region of neurons. In this projection certain portions of the neuronal tree (notably regions 2,4 , and $5 \mathrm{~A}$ ) appear foreshortened. Drawn with the aid of a serialsection reconstruction. 
even at $100 \times$, lies beneath the lateral calyx and lateral to the anterior border of the pedunculus. Here each fiber gives rise to an anterior continuation, designated 4 , a dorsal branch, designated 5 , and a very short medial stem. This stem immediately gives rise to a branch 7 and in at least three of the neurons (through bifurcation) to a branch 6 . Branches 5,6 and 7 supply the calyces.

The four branch 4's continue medioanteriad in approximately the transverse plane until passing about the posterior one-third of the adjacent portion of the $\alpha$ lobe. Then they curve directly ventrad and disperse into the neuropile in this region. The bifurcation of a branch 4 in this area has been clearly observed twice and strongly suggested in other instances. Consequently these four fibers probably do not merely separate but actually terminate here, at least partly.

The four branch 5's extend directly dorsad from their point of origin and then curve postero-mediad toward the base of the apposed calycal walls (figs. 14, 15). While passing adjacent to the lower border of the lateral calyx, before reaching the region of calycal apposition, each fiber gives off a dorso-postero-lateral branch 5A. The $5 \mathrm{~A}$ branches immediately enter the lower border of the lateral calyx and extend along this border (fig. 16) posteriad and slightly laterad. In two preparations proof of the intracalycal branching of one of these fibers has been obtained, and in a few other cases images indicating a probable branching have been observed. In the clearest example, a branch $5 \mathrm{~A}$ bifurcates $\sim 85 \mu$ from its point of origin into antero-lateral and postero-lateral forks; the former curves anteriad and then anteromediad, being joined by at least two widely-spaced parallel fibers which may well derive from other $5 \mathrm{~A}$ fibers. In the other case in which a $5 \mathrm{~A}$ branch has been clearly seen to branch (likewise $\sim 85 \mu$ from its origin), a similar widely-spaced group of four fibers emanates in the adjacent section in close proximity to this branching point. These four fibers thus probably represent forks of the $5 \mathrm{~A}$ fibers. They sweep along the calycal wall first latero-anteriad and finally medio-anteriad, the largest, lateral-most fiber emitting one branch and bifurcating once (fig. 28). In addition to dispatching these anterior forks, which are probably consistently present, the $5 \mathrm{~A}$ branches extend far posteriad: in two preparations at least some were traceable, perhaps after additional bifurcation, to within $\sim 90 \mu$ of the posterior calycal border.

Having given rise to branch $5 \mathrm{~A}$, each branch 5 continues to the base of the region of calycal apposition, where it forks into branches $5 \mathrm{~B}$ and $5 \mathrm{C}$. The four $5 \mathrm{~B}$ branches pass between the apposed calyces, maintaining the postero-medio-dorsal course of their parent branch 5's (fig. 17). Upon reaching a level a few tens of microns from the dorsal border of this "intercalycal region" they assume a transverse course, and at least some of them or their branches continue postero-medioventrad. The $5 \mathrm{~B}$ fibers eventually become lost in the intercalycal region, presumably branching into one or both apposed vertical calycal walls. Twice a 5B fiber has been observed giving off a branch or bifurcating and in some other instances this has seemed to be the case, but these products could not be traced satisfactorily.

The four 5C branches (fig. 17, inset) extend antero-mediad into the lower wall of the medial calyx and travel along the lower border of the wall for some distance. Whereas at first they maintain their antero-medial direction, toward the anterior end of the calyx they curve mediad and at least some but possibly all of them finally assume a postero-medial and then posterior course, along the ventro-medial calycal border. Whether the $5 \mathrm{C}$ fibers fork during this course is unclear.

The branch 6's are less well understood than the other main branches, owing to the small size of some of them. In nearly every case only three could be distinguished, but in two preparations four such fibers are clearly visible and this may well be the normal number. From their point of origin (fig. 14) these branches extend mediad, in a curve directed first anteriad and slightly dorsad and later dorsad and somewhat posteriad, to a point behind the $\alpha$ lobe. Here, just anterior to the top of the pedunculus and below the lower walls of the calyces, the largest fiber and very possibly also the smaller ones branch. Branches of the largest fiber with particular courses have each been observed several times although it is uncertain whether they always arise in a 
consistent arrangement from this branching area. These branches comprise: (i) a medial fiber which seems to enter either the ventral wall of the medial calyx or the ascending span of the anterior division of the tractus olfactorio-globularis (described below) or, through forking, both; (ii) a branch which passes into the intercalycal region dorso-medio-posteriorly; and (iii) a dorso-lateral branch which immediately penetrates the lower wall of the lateral calyx. This latter branch has often been observed to give rise to a fork immediately upon entering the calycal neuropile. In any case it does not travel along the external border of the calycal wall but rather extends directly through the midst of the zona externa (fig. 18). In favorable preparations it can eventually be observed to branch once or twice and dissipate into this layer.

The four branch 7's, from their point of origin in the main branching region of the neurons, take a nearly transverse, posteromedial course to a point behind the top of the pedunculus (figs. 31, 32). Here, at the base of the region of calycal apposition, at least two but probably all bifurcate into dorsal 7A branches and medial 7B branches. The four 7B branches enter the lower wall of the medial calyx and extend along its lower border in an arc curving mediad and then anteriad. In addition to their anterior progress, at least two and perhaps all extend as far mediad as the medial border of the medial calyx. The 7A branches, of which only two are known certainly to exist, extend upwards into the region of calycal apposition and continue in a generally dorsal, perhaps slightly posterior direction. A branch $7 \mathrm{~A}$ has been found to extend at least $110 \mu$ in one case and has been followed for $\sim 150 \mu$ in another. In one instance, a branch 7A has been clearly observed to emit a sizable, short perpendicular branch into the vertical wall of the medial calyx, the latter branch immediately ramifying into the zona externa. In addition, there is strong evidence in a single case for the emission of a large lateral branch to the vertical wall of the lateral calyx.

Each numbered group of quartet cell branches discussed above has been observed consistently in over a dozen hemispheres of $P$. americana. In addition to these established branches, however, others, usually much narrower, have occasionally been observed in certain regions, generally in particularly good preparations. Some have been found in two or more brains, which suggests that they are constantly present but ordinarily too poorly preserved or stained to be apparent. Outside the calycal area, all these branches have been confined to region 1 and the base of regions 3 and probably 2 . Within the calycal area, such branches, seemingly destined at least in some cases for the calycal neuropile, have been found arising from region 7 . In addition, there is virtual proof in one preparation and highly suggestive evidence in two others for the presence of a single branch in region 5 , between the $5-5 \mathrm{~A}$ and $5 \mathrm{~B}-5 \mathrm{C}$ branching points, which immediately enters the lateral calyx and there branches.

Although the preparations cannot reliably provide accurate reflections of fiber diameters in the living state, some general conclusions are possible, based on approximately 80 measurements from the various regions of the quartet neurons. A noticeable diameter range is usual among fibers in single bundles (see, for example, fig. 17, inset) and is sometimes so striking and consistent (for example in region 6) as to exclude artifact as the primary basis. Furthermore, the diameters of the largest fibers within bundles from different numbered regions fall within the same order of magnitude, typically assuming values of $\sim 3$ to $\sim 7 \mu$. The question of whether the quartet neurons may be individually unique, and may differ among themselves qualitatively or quantitatively in a consistent manner, requires further study.

As the above description indicates, most quartet cell fibers destined for the calyces extend up to and then travel within the external margin of the zona externa, including the region where the zonae externae of both calyces are apposed. In such locations the fibers have shown diameters up to $6 \mu$. Here at the external calycal margin these fibers, having only rarely emitted readily visible offshoots into the calycal interior, eventually become lost to tracing. Presumably these externally located fibers do not actually end at the calycal margin but finally turn into and disperse within the interior of the zona externa, along with the one or more quartet 
cell fibers known to pass directly into the midst of this layer from outside the corpus pedunculatum. Fibers in the interior of the zona externa established certainly to belong to quartet neurons have shown diameters up to $3.5 \mu$. I have perceived no single preferred orientation which such fibers or their ramifications share.

Curious bodies resembling tiny nuclei occur embedded within quartet cell fibers. Observations have been made on over 30 such bodies distributed among seven silverimpregnated brains of $P$. americana.

The bodies (fig. 19) are typically ellipsoidal in shape and average about $3.2 \mu$ in length and $2.1 \mu$ in diameter. Usually they are surrounded by a shrinkage space, whose volume may exceed theirs. In favorable cases they exhibit a distinct, darkly stained peripheral membrane and one or two (rarely more) darkly stained internal particles. They have also been observed a few times in identified quartet cell fibers of $P$. americana in dyed, 1 - to $2-\mu$ Epon sections of tissue fixed in glutaraldehyde and post-fixed in osmic acid; in this material they stain similarly to typical nuclei. Although in the silver preparations the bodies sometimes lie against the peripheries of their fibers or even, where fiber shrinkage is very pronounced, protrude as a "blister," they frequently lie well within the fibers. Nevertheless, in neither type of material above have I found signs of either a thin cytoplasmic layer applied to their membranes or a connection with the outside of their fibers.

These inclusions are interestingly distributed. Of the more than 30 discovered in the silver preparations while scanning with equal attention the different regions of the quartet neurons, about a third each occurred in regions 5,6 and 7 and their respective branches, while a single presumed example was present at the very proximal end of region 4 . No bodies were observed in the soma or in region 1,2 , or 3. Furthermore, within regions 5,6 and 7 they were invariably situated in the distal half. Within the calycal zone they have been observed in or next to the $5-5 \mathrm{~B}-5 \mathrm{C}$ and $7-7 \mathrm{~A}-7 \mathrm{~B}$ branching points; further distad within the $5 \mathrm{~B}$ and $7 \mathrm{~A}$ regions; in branches from region 6 located within the intercalycal region and probably (in one case) within the lateral calyx; and in re- gion 7B. Thus, with the single exception noted they have been found only in those parts of the quartet neurons which are close to, in contact with, or actually within the calyces. This conclusion agrees with that reached earlier after careful examination of the somata and all major branches of the quartet neurons in several silverimpregnated brains of Periplaneta $s p$.

Two or more bodies have sometimes been seen in one neuron, but never more than about two or three have been found closely approximated within one branch or branching point.

Within bundles of quartet cell branches the bodies have been seen in only the larger fibers, and they may be limited to one or two of these neurons. But because they are often poorly preserved in the silver preparations and consequently only sporadically discovered, the present observations cannot indicate the degree of constancy of their presence or distribution. Previous observations on silver preparations of Periplaneta sp., in which the bodies are better preserved, suggest that in that species their presence in close association with at least the $5-5 \mathrm{~B}-5 \mathrm{C}$ and $7-7 \mathrm{~A}-7 \mathrm{~B}$ branching points and initial branching area of region 6 is indeed consistent, and I suspect this to be the case also in $P$. americana.

The nature and significance of these curious bodies remain obscure. In insects and other animal groups neurons are sometimes invaginated by other cells (see Bullock and Horridge, '65), and the bodies may represent invaginating nuclei whose continuity with glial or other cytoplasm outside the nerve fiber is so tenuous as to be easily overlooked or invisible with light microscopy. Other explanations are possible. Either ultrastructural or developmental information could shed light on this problem.

\section{The tractus olfactorio-globularis and its emanations to the calyces}

In addition to the quartet-cell fiber bundles, the external calycal margins exhibit a second series of fiber groups variously containing from one or two dozen to several score visible fibers. In recognition of their larger fiber complements these groups will be referred to as calycal tracts as distinguished from bundles. All are believed to 
represent emanations from the tractus olfactorio-globularis (sensu lato).

The tractus olfactorio-globularis, sonamed by Hanström ('28), comprises in the strict sense a fiber tract discovered by Flögel (1878) in Blatta orientalis and other insects and later shown through the work of many authors to be a characteristic feature of the pterygote brain. It is considered chiefly to connect the calyces with the "olfactory" or antennal lobes of the deutocerebrum (figs. 1, 5), which receive sensory information from the antennae. In 1948 Jawlowski reported that in P. americana the tract, which he called "inner olfactoro-globular tract," divides close to the central body (figs. 1,5) into an anterior and a posterior branch; of these, only the first had previously been known in cockroaches. Whether the posterior branch should be included under the name tractus olfactorio-globularis (or, in Jawlowski's terminology, inner olfactoro-globular tract) can properly be decided only after a predominant origin from the antennal sensory lobe has been demonstrated more convincingly than Jawlowski ('48, '53) has yet done. But pending a clarification of this problem, in keeping with the spirit of Jawlowski's usage both "branches" will here be subsumed under the name tractus olfactorio-globularis (sensu lato), being referred to respectively as its anterior and posterior divisions.

Upon entering the protocerebrum, the anterior division ascends immediately behind the central body (figs. 20, 21) and shortly begins to curve laterad, eventually passing just beneath the calyces on the anterior side of the emerging pedunculus (fig. 22). Here the tract sends fiber groups into the calyces and then, as Jawlowski (48) has found, continues further into the neuropile of the protocerebral lobe (fig. 23).

Of the total path of this division before and after entering the protocerebrum, only the portion dorsal to the central body has been examined in detail in this study. In careful observations from several preparations, apart from those fibers which extend into the calyces only rarely has evidence been obtained of even a single fiber possibly leaving or entering the division in the portion between the central body and calycal region.

After emitting processes into the calyces, the anterior division, reduced in size, turns ventrad and travels for some distance within the protocerebral lobe (figs. 23, 40). Observations on both hemispheres of one particularly favorable preparation show the tract to extend posteriad and somewhat ventrad for $\sim 150-200 \mu$ before becoming split up in the protocerebral neuropile and lost to tracing.

The posterior division of the tractus olfactorio-globularis has not often been strongly impregnated in my preparations. Nevertheless, careful study of about a dozen hemispheres, mostly frontally sectioned, has given some useful information on its behavior dorsal to its separation from the anterior division.

In following the posterior division dorsad, it is first seen to separate from the anterior division at approximately the height of the lower limit of the central body. It diverges from the anterior division laterad and slightly posteriad while maintaining its dorsal course (fig. 24). Finally the tract's lateral curvature brings it near the postero-medial border of the pedunculus. Here, in one hemisphere, a darkly stained fiber traceable far ventrad within this tract is clearly seen to emit a collateral which extends antero-dorsad and can be followed with near certainty into the interior of the zona externa in the lateral region of the lower wall of the medial calyx. Slightly laterad in this hemisphere, a second darkly stained fiber which extends out of the tract does certainly travel up to and enter this region of the medial calyx. These observations suggest that at the top of the posterior division's ascending portion fiber collaterals which extend into the lower wall of the medial calyx may normally occur.

Having curved laterad and perhaps normally emitted collaterals, as described, into the medial calyx, the posterior division continues dorso-laterad to a point behind the top of the pedunculus. From this precise point, a fiber group $\sim 25 \mu$ wide extends generally dorsad towards the lateral half of the base of the zone of calycal apposition. Critical observations on the origin of this group, to be treated below under the designation tract 4 , have established with virtual certainty that as Jawlowski ('48, '53) schematically depicts, it originates (at least in large part) from the posterior divi- 
sion. Whether whole fibers or simply collaterals leave the latter to form tract 4 is unknown. Concomitantly, it is uncertain whether some or even all fibers of this division continue laterad beyond the point of origin of tract 4, as Jawlowski ('48, '53) depicts schematically but does not actually prove. Fibers have been seen leaving this region laterally and these might represent a lateral continuation of the division.

\section{Topography of the calycal tracts}

The calycal fiber tracts emanating from the tractus olfactorio-globularis (sensu lato) exhibit some variability which makes their topographical study difficult. Consequently my efforts have been directed toward a detailed understanding of tracts in a limited region, namely the lateral calyx excluding its medial, vertical wall. First, with two types of exceptions, all defined groups of extrinsic fibers discovered in this portion of the lateral calyx will be described as they typically appear when present. The numbering scheme for these tracts is shown in figure 3 . These descriptions will be followed by a treatment of observed variability. The exceptions mentioned comprise bundles of quartet cell fibers and any other, comparatively minor groups of extrinsic fibers which encroach slightly into the region of interest following passage upwards between the apposed vertical calycal walls. Finally, fiber tracts in the remainder of the calyces will be treated briefly. It should be kept in mind during the following account that not every fiber necessarily extends the whole length of its tract before passing into the interior of the zona externa.

(a) Typical conditions in portion of lateral calyx. Tract 1 . This tract originates

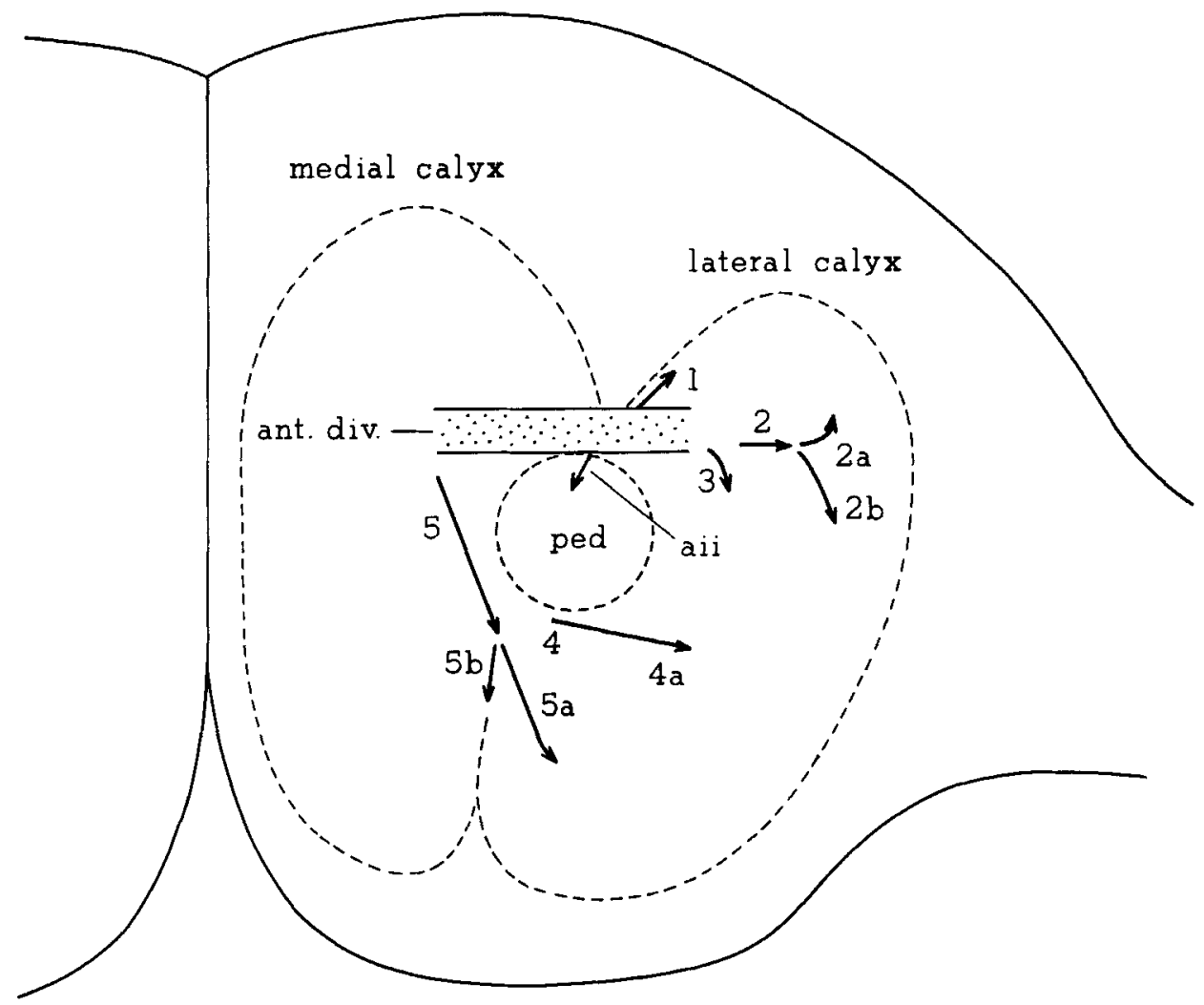

Fig. 3 Diagram showing numbering scheme of calycal tracts in the lateral calyx, represented as though projected onto a transverse plane. Anterior is upwards, while medial is to the left. Abbreviations: ped, pedunculus; ant, div., anterior division of tractus olfactorioglobularis; aii, anterior intercalycal fiber influx; $1,2,2 \mathrm{a}, 2 \mathrm{~b}, 3,4,4 \mathrm{a}, 5,5 \mathrm{a}, 5 \mathrm{~b}$, various tracts. 
in the lateral calyx immediately adjacent to the base of the zone of calycal apposition and in proximity to the transverse section of the anterior division of the tractus olfactorio-globularis. Its fibers appear to derive, as least in the greatest part, from the middle segment of this transverse section, from which they extend upward into the wall of the lateral calyx. Whether they represent collateral processes is unknown. The tract continues anteriad and dorsad along the calycal wall in a slightly lateral direction, remaining fairly close to the region of calycal apposition. Upon reaching the front surface of the calyx (fig. 25) it disperses into the zona externa. When present in a well-defined form, tract 1 has been found to range in width from $\sim 23 \mu$ to $\sim 40 \mu$.

Tract 2. This tract originates out of fibers which appear to emanate from the anterior division in the vicinity where it begins its ventral curve lateral to the pedunculus; a few observations suggest that at least some fibers in tract 2 arise as branches of fibers within the division (see fig. 26). The fibers giving rise to tract 2 extend laterad into the calyx, and it is almost directly laterad that this tract extends (figs. 23, 26, 27, 34). In its "typical" form tract 2 is $\sim 25 \mu$ wide.

After traversing the lower wall of the calyx for some distance, tract 2 splits (whether through individual bifurcation or merely separation of fibers remains unknown) into an antero-lateral continuation, tract $2 a$, and a postero-lateral continuation, tract $2 b$. Tract 2 a (figs. 28, 29), which is $\sim 20-30 \mu$ wide near its origin, extends generally anteriad to the front surface of the calyx, where it disperses. Tract $2 b$, which is usually $\sim 30-35 \mu$ wide proximally, curves posteriad and continues some distance posteriad (figs. 28, 27, 16). Eventually it extends along the lateral wall of the calyx and probably following a bifurcation, there disperses (fig. 30).

Tract 3. This prominent tract (fig. 16) originates adjacent to the anterior division near the origin of tract 2 , similarly deriving from fibers which appear to extend out of the division as it begins to curve ventrad lateral to the pedunculus. Whether these fibers represent collateral processes is unknown. Whereas the fibers giving rise to tract 2 extend laterad into the lateral calyx, those giving rise to tract 3 curve posteriad into their tract. Tract 3 is quite wide, measuring $\sim 50-60 \mu$ proximally. It extends along the lower wall of the calyx rather directly posteriad for approximately $100 \mu$ before possibly bifurcating and eventually dispersing into the zona externa. This tract is characteristically associated with the $5 \mathrm{~A}$ branches of the quartet cells.

Tract 4a. Upon reaching the lower border of the lateral half of the region of calycal apposition just posterior to the pedunculus, tract 4 (fig. 31) (see above) begins to split up. At least in part this may occur through bifurcation of single fibers. One of the products of this tract is tract $4 a$ (fig. 32), which extends into the lower wall of the lateral calyx directed laterad and slightly posteriad, immediately begins to curve gradually laterad, and eventually assumes an antero-lateral course. Tract $4 a$ 's course brings it into close association with tract 3 , which it appears to traverse, soon dispersing in the zona externa. Proximally tract $4 \mathrm{a}$ is $\sim 15-25 \mu$ wide.

Tract $5 a$. As the dorsal and lateral course of the anterior division brings it to a point just beneath the lateral portion of the medial calyx's lower wall, close to the medial peduncular column, a large number of fibers belonging to this division leave it posteriorly to form a very prominent calycal tract, tract 5 . That many or even all of these fibers may represent collaterals is suggested by the occasional discovery here of single fibers which seem to give off a branch directed toward the origin of the tract. Tract 5 extends posteriad along the lateral-most region of the lower wall of the medial calyx. This course eventually takes it somewhat laterad toward the base of the region of calycal apposition, posterior to the top of the pedunculus (figs. 31,32 ). Upon reaching this point, the tract passes into the region of calycal apposition and there bifurcates, giving rise, just posterior to the splitting-up of tract 4 , to tract $5 a$. The latter, a prominent tract, enters the lower wall of the lateral calyx directed posteriad and laterad and continues along the wall in a lateral, slightly posterior direction (fig. 33). Finally it ascends the lateral wall of the calyx for some distance and there disperses into the zona externa. Near its origin tract $5 \mathrm{a}$ is $\sim 30-35 \mu$ wide.

(b) Variability. In each of six hemis- 
pheres examined, the presence of normal tracts 3 and 4 a could be confirmed. Similarly, in each of five hemispheres examined, the presence of a normal tract $5 \mathrm{a}$ could be confirmed. The remaining tracts, however, exhibited some interesting variability, which was studied in ten hemispheres. One of these will be excluded from consideration in view of uncertainty in the observations due to appreciable shrinkage of extrinsic fibers. Because metallic impregnation is a notoriously variable technique, it may be emphasized here that the considerable reliability of staining of given fiber types within successfully impregnated regions and the nature itself of some of the observed variability both serve to exclude variable staining of an unvarying set of tracts as a sufficient explanation for the conditions to be described.

of the nine hemispheres, only seven show a "typical" tract 2 . In all seven cases, tract 2 gives rise to tract $2 b$. In only five of the seven cases, however, does a tract $2 \mathrm{a}$ as such appear to be present: in the sixth case (fig. 34 ) tract $2 \mathrm{a}$ is presumably represented by a wide band of scattered fibers which is not as massive as a "typical" tract $2 \mathrm{a}$, while in the seventh case the presence of even such a band of scattered fibers is uncertain.

In these seven hemispheres with a "typical" tract 2 , tract 1 can be observed in a well-defined form in only three. In another two of the seven, tract 1 appears to be represented by a number of fibers not grouped into a very well-defined tract, while in the two remaining cases the presence of even such fibers remains uncertain. Moreover, there are suggestions of a negative correlation between the presence of a well-defined tract 1 and that of a well-defined tract $2 \mathrm{a}$ : in one of the seven hemispheres both tracts seem to be present, but in each of the other six hemispheres only the one or the other occurs in a well-defined form (in four tract $2 a$, in two tract 1 ).

The two hemispheres not showing a "typical" tract 2 exhibit some interesting features which will be considered in detail.

1. The first hemisphere exhibits good fixation and impregnation, with only average fiber shrinkage. A comparatively narrow fiber bundle nearly identical in position and orientation to a typical tract 2 is present in the lateral calyx. These fibers can be observed laterally to curve posteriad and continue posteriad for some distance as a very loose bundle occupying a position similar to that of a typical tract $2 \mathrm{~b}$. However, there is no evidence whatever for the presence of a tract $2 \mathrm{a}$ or even a diffuse representative of one, although this calycal region is well impregnated and tract 1 can be observed quite clearly in an adjacent area. But more surprising is the existence of an extra tract on the lateral side of tract 3. It resembles in size and orientation a "typical" tract 2b but is located much further mediad. Its fibers seem to originate in the anterior division of the tractus olfactorio-globularis, in the general vicinity in which tracts 2 and 3 normally originate. Interestingly, the $5 \mathrm{~A}$ branches of the quartet cells, rather than being associated with tract 3 , are located on the lateral side of the extra tract. Finally, a transverse tract $\sim 24 \mu$ wide, which has not been observed in any other hemisphere, is located at the level of the posterior side of the pedunculus (fig. 35). This tract, whose exact origin medially is uncertain, can be traced laterad from the region of tract 3 and the other "extra" tract and appears to disperse among the fibers meagerly representing the typical tract $2 \mathrm{~b}$. The other hemisphere of this brain is normal with respect to tracts $1,2,2 \mathrm{a}, 2 \mathrm{~b}$, and 3 , except that tract $2 \mathrm{a}$ is poorly developed.

2 . In the second hemisphere of interest, the fibers are sufficiently well fixed and very intensely stained. There is only unconvincing evidence for the presence of even an extremely reduced tract 2 and no sign of tracts $2 \mathrm{a}$ and $2 \mathrm{~b}$. Tract 1 , however, is well defined and fairly massive. Remarkably, at the lower surface of the lateral calyx near its anterior end, tract 1 appears to give rise to a lateral group of fibers (whether these are collaterals is unknown) which turn posteriad a little laterally and extend posteriad, following the normal course of tract $2 a$. These fibers subsequently continue on along the normal course of tract $2 b$ to disperse terminally not far from the level of the posterior surface of the top of the pedunculus. This extra tract can be observed clearly and unquestionably arises at the front of the calyx rather than in the usual vicinity of tract 2 . The corresponding tracts in the opposite hemisphere are normal except that tract 1 does not 
occur in a well-defined form and may be absent.

Different interpretations of the observed variability are possible. On the one hand, fibers reaching a given area may always belong to the same invariable set of neurons but simply arise from variable points along their parent fibers and (or) reach their destination following variable routes. The mechanism by which the same destination could be consistently reached would be of some interest. On the other hand, fibers reaching a given area may not always belong to the same invariable set of neurons. In this case the nature of the observed variability suggests that some mechanism may nevertheless insure a constant innervation density for a given calycal area. Two lines of evidence can support such a conclusion: first, the finding that although tracts 1 and $2 \mathrm{a}$ each terminate distally in the same section of the calyx they tend not to appear in a well-developed form simultaneously, and second, the seeming relationship between the courses or areas of dispersion of extra tracts and those of the normal tracts which in their hemispheres are lacking or reduced. In any event, failure of the highly atypical conditions in the two hemispheres showing extra tracts to occur simultaneously in the contralateral hemispheres suggests that the observed variability may not be genetic in origin.

(c) The remaining calycal areas. Fiber tracts comparable to those described for the major portion of the lateral calyx also occur over the entire medial calyx and the remainder of the lateral calyx. Figure 36 shows a typical example from the medial calyx. Since, aside from quartet cell branches, the only groups of extrinsic fibers I have ever seen passing into either calyx appear to extend directly from the tractus olfactorio-globularis (sensu lato), all tracts in these remaining areas presumably represent merely additional emanations of the tractus olfactorio-globularis. Due to the expected variability in these remaining tracts, a detailed study of each has been impracticable. Nevertheless, that the tracts in these areas are simply counterparts of the emanations already described in the lateral calyx is supported by the similarity between both calyces in their ultrastructurally distinguishable nerve fiber classes (Weiss, unpublished observa- tions) and by the following brief descriptions of representative examples of tracts in these remaining areas.

As previously mentioned, just posterior to the pedunculus tract 4 begins to split up, one product, tract $4 \mathrm{a}$, passing in to the lower wall of the lateral calyx. A second product, however, extends generally dorsad between the apposed vertical calycal walls. There it disperses, presumably, as one particularly favorable hemisphere strongly suggests, into both apposed walls. In addition there are suggestions, requiring confirmation, of fibers which extend posteriad within the base of the region of calycal apposition to tract 5 , with which they seem to become associated, and of fibers which extend across the base of the appositional region to the medial calyx.

During its course, described above, along the lateral-most region of the lower wall of the medial calyx, tract 5 sends at least one fiber group into this wall. In bifurcating posterior to the pedunculus, tract 5 gives rise, in addition to tract $5 \mathrm{a}$, to a prominent tract $5 b$ which extends more or less dorsad between the apposed calycal walls (fig. 37) and ultimately disperses within both calyces.

Finally, as the anterior division of the tractus olfactorio-globularis passes beneath the base of the region of calycal apposition just anterior to the origin of the pedunculus, a large number of fibers leave the division more or less perpendicularly to enter the region of calycal apposition directed postero-dorsad. After coursing between the apposed calycal walls, these fibers ultimately disperse into both calyces. That many if not all originate as collaterals is strongly suggested by several appearances in the preparations. Since I am not yet certain that this prominent fiber inflow becomes organized into only one coherent tract, it will not be given a number but will simply be designated the anterior intercalycal fiber influx (fig. 23).

The intercalycal fiber groups now described are believed to account for most or all fiber tracts situated between the apposed vertical calycal walls.

Scattered fibers similar in size to calycal tract fibers are commonly observed at the external margin of the zona externa. They sometimes run parallel and in proximity to the tracts, making the latters' strict 
delimitation partly arbitrary. Presumably most of these fibers similarly derive from the tractus olfactorio-globularis (sensu lato), perhaps by way of calycal tracts, although some may represent branches of quartet cell fibers or of extrinsic fibers of unknown origin to be described below. I assume that these scattered fibers eventually terminate in the midst of the zona externa.

\section{General comments on the origin of the calycal tracts}

In the preceding section the origin of individual calycal tracts has been described with caution. Caution is necessary because of the difficulty here of tracing individual fibers clearly over a sufficient distance and because of the absence of proof that every fiber within a tract shares an identical origin. Evidence of the latter kind represents an ideal which in practice is probably unachievable with light microscopy. The best that can be wished for is establishment of the immediate origin of some fibers in a calycal tract and confirmation for the remaining fibers that their behavior is consistent with such an origin and that any alternate origin is unlikely. This represents the level of evidence I have sought to obtain.

Every calycal tract studied has been found to originate in intimate association with the tractus olfactorio-globularis (sensu lato) (e.g., figs. 23, 26). In some instances at least a predominant origin from it (e.g., calycal tract 5 and the anterior intercalycal fiber influx) has been grossly apparent. In the case of calycal tracts 1 , 2,3 , and 5 and the anterior intercalycal influx, individual fibers have been seen extending directly out of the anterior division toward or into the originating calycal fiber group. Suggestions that such fibers arise as collaterals (e.g., figs. 26, 38, inset) have found confirmation in ultrastructural study of the anterior division. This has established for several fibers the presence of an oblique or perpendicular collateral which extends toward the calycal surface (fig. 38).

Apart from quartet cell fibers and those emanating from the divisions of the tractus olfactorio-globularis, only one or two additional extrinsic fibers, of uncertain origin, have ever been found entering the cal- yces. Moreover, I have been unable to discover any other fiber groups near the calyces which might be suspected of elusively passing into them either directly or after becoming mixed with either division of the tractus olfactorio-globularis. Thus the possibility that any significant proportion of calycal tract fibers might elusively stem from a source other than the tractus olfactorio-globularis (sensu lato) can be reasonably excluded.

On these grounds I consider the observations to warrant the following conclusion: the calycal tract fibers taken collectively originate exclusively, or almost exclusively, in the tractus olfactorio-globularis (sensu lato).

\section{Terminations of the calycal tracts}

Regardless of the individual courses of the calycal tracts, their fibers all eventually disperse into the zona externa. In my preparations, fibers derived from these tracts typically constitute the most prominent fiber class in the zona externa. Although distributed within this layer throughout all areas of both calyces, they are particularly conspicuous where a tract turns into the midst of the zona externa to disperse (figs. 30, 39). The fibers course in various directions without any apparent common orientation. Bifurcations have been observed.

The diameter of fibers within calycal tracts mostly does not exceed $2.5 \mu$ and commonly falls far below this; it has never been found to exceed $3.5 \mu$. Fibers entering the interior of the zona externa from calycal tracts rarely if ever exceed $2 \mu$ in diameter and ordinarily measure much less.

\section{Extrinsic calycal fibers of unknown origin}

In several preparations individual, sharply stained fibers within the zona externa have been observed extending over an appreciable distance in one direction, parallel to the zona interna. Such fibers are distributed throughout each calyx. A dozen representative examples selected from two preparations and given detailed study range in maximum diameter from $1 \mu$ to nearly $3 \mu$ and invariably lie (at least proximal to their first branching point) in the internal half of the zona externa, often 
close to the zona interna. In 11 cases the fiber is unambiguously traceable proximally to where the fibers of the zona interna converge to form the peduncular column, and in the remaining case this course appears probable, but in no instance is the further course clear. From this proximal region the fibers extend outwards through the zona externa in more or less radial lines. Nine of the fibers have been seen to branch distally once or more within the zona externa and appearances suggest such branching in two other cases. In two instances from these dozen examples and a third from other observations, it appears that a narrow branch might be emitted into the zona interna. Conclusions on this point are rendered hazardous, however, by the often close proximity of the fiber to the zona interna; the common lack of a sharp boundary between zona interna and zona externa; and the problem of misleading images resulting from optical superposition of these layers in some sections.

These radiating fibers (figs. 40,41 ) seem to number not more than $\sim 20-40$ per corpus pedunculatum. Whether they derive from the tractus olfactorio-globularis (sensu lato) or from some other as yet undiscovered source remains unknown. Nevertheless, their consistent radial orientation and passage, from the very first, through the midst of the zona externa instead of along its external margin (although some distal branches may prove to reach and course along this margin) distinguish them unequivocally from other extrinsic calycal fibers and warrant their recognition as a distinct class.

\section{Intrinsic fibers of the zona externa}

The fiber classes thus far considered in detail originate outside the corpus pedunculatum. In addition to these, two classes of narrow fibers belonging to intrinsic globuli cells of the corpus pedunculatum have been distinguished in the zona externa.

As mentioned above, very thin processes can be seen in my preparations to pass perpendicularly from zona interna into zona externa. They measure but a fraction of a micron in diameter and have always been lost soon after entering the zona externa. Findings from Golgi preparations of Blatta orientalis (Sánchez y Sánchez, '33) and ultrastructural observations on $P$. ameri- cana (Weiss, unpublished) clearly indicate that as my reduced silver preparations also strongly suggest, these perpendicular processes are collaterals of the tangentially oriented intrinsic fibers of the zona interna.

In addition, there is present in the zona externa, in all areas of each calyx, a class of fibers which tend to be oriented tangentially and likewise measure but a fraction of a micron in diameter (figs. 42,43 ). They can often be followed in one direction for long distances within the zona externa, through which they course toward the junction of the calyces with the pedunculus (fig. 44). They resemble in size the tangentially oriented fibers of the zona interna and in fact sometimes occur so closely associated with them as to create the appearance of a single class of tangential fibers which decrease in concentration from the zona interna to the zona externa. The distal behavior of these tangential fibers of the zona externa will be described before considering their origin.

In several sections from each of two particularly favorable preparations, these fibers are seen, upon reaching the junction of the calyx with its peduncular column (fig. 45), to become applied to the external surface of the zona interna as a superficial layer. In these and other preparations, as the zona interna emerges from the calyx ventrally to form the peduncular column and this, having fused with its counterpart from the other calyx, continues its course distad within the pedunculus, the superficial layer likewise continues ventrad, along the walls (including, to some extent, the apposed walls) of approximately the posterior half of the peduncular columns, to form the most superficial layer of the pedunculus. As the two peduncular columns fuse within the pedunculus, the layer becomes more and more excluded from their appositional region and finally restricted to the outer perimeter of the posterior half of the pedunculus (figs. 46, 47 ). It extends along the greater part of and perhaps entire pedunculus, becoming increasingly restricted during its course to the postero-lateral sector of the latter.

In my preparations this peripheral fiber layer appears lighter in color than the underlying layer. Proximally, adjacent to the zona externa, it exhibits a rather loose texture and might include synaptic neuropile. 
Immediately underlying the peripheral layer is a more darkly stained layer. There are strong indications that this layer too derives from narrow tangential fibers within the zona externa which have become applied to the zona interna at the junction of the calyx with its peduncular column. This derivation is not certain, however, for it is difficult to exclude the possibility that it derives at least partly from the externalmost fibers of the zona interna. The second layer, from its origin at the top of the peduncular columns, follows the same course as the overlying lighter layer: it is restricted to the posterior half of the peduncular columns (except proximally where it extends forward somewhat between them) and eventually becomes localized in the postero-lateral sector of the pedunculus (figs. 46, 47). I have established definitely that this second layer extends the entire length of the pedunculus. The behavior of both layers further distad remains to be clarified.
Establishment of the entry of narrow tangential fibers from the zona externa into the special posterior zone of the peduncular columns has proven possible only in generally posterior areas within certain favorable sections. Nevertheless, such fibers from all areas of the calyces have been observed to approach the peduncular columns. This suggests that all these fibers, even those from strictly anterior calycal areas, pass into the same special posterior zone. Some views have in fact seemed to show fibers from calycal areas anterior to the columns becoming directed towards and passing into the second, comparatively darkly stained layer in the posterior region of the latter. Although it is difficult to establish in the available preparations, I suspect that all or virtually all fibers of this class do enter the special posterior zone of the columns rather than another sector of their perimeter. In any event it is clear that the fibers do leave the calyces along with the zona interna, to

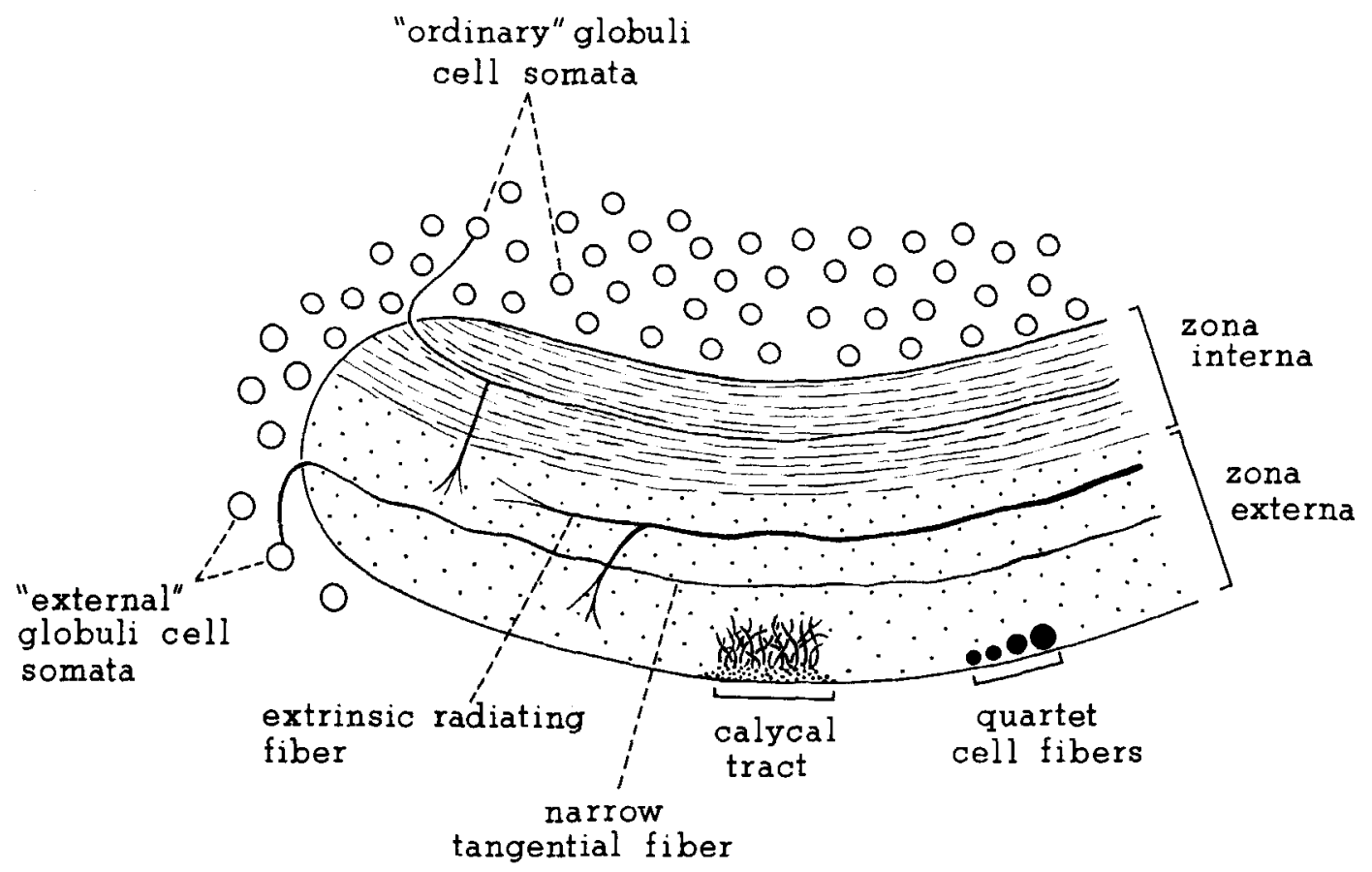

Fig. 4 Diagram of a generalized section through the wall of a calyx of $P$. americana, summarizing known fiber constituents. The pedunculus would be to the right and the calycal rim is seen at the left. The fiber arrangement of the "ordinary" globuli cell is shown in part after the findings of Sánchez y Sánchez (33) on Blatta orientalis and those of Weiss (unpublished ultrastructural observations) on $P$. americana. Although the narrow tangential fibers of the zona externa presumably possess calycal collaterals these remain to be demonstrated and consequently are not shown here. 
which they have become applied, to constitute a component part of the peduncular columns.

It has previously been known (e.g., Hanström, '28; Arnold, '60) that in histological preparations the pedunculus and $\alpha$ and $\beta$ lobes of $P$. americana display longitudinal layers of alternately lighter and darker appearance (see fig. 20). The two posterior fiber layers described here seem to correspond to the numerous remaining longitudinal layers. Some interesting implications arising from such a correspondence are suggested elsewhere (Weiss, '72b).

In numerous sections mostly from two preparations, the narrow tangential fibers of the zona externa are seen to extend to and sometimes turn along the margin of the neuropile at the peripheral rim of the calycal walls (fig. 48). Now it is an interesting fact, first recognized in a cockroach by Flögel $(1876,1878)$ in Blatta orientalis, that the globuli cell somata in at least some species are not confined to the concavities of the calyces. In P. americana the somata "overflow" each calyx around its entire circumference and lie adjacent to the rim of the zona externa; sometimes they extend far along the external surface of the zona externa (figs. 7, 48, 49) (cf. Brousse-Gaury, '71). In several sections from preparations showing least shrinkage, these somata appear larger than most if not all more central ones (fig. 50) (for approximately comparable observations on Blatta orientalis see Sánchez y Sánchez, '33). Fiber bundles from these "external" somata have been found several times to extend to (fig. 49) and travel along the peripheral rim of the zona externa, the very region to which narrow tangential fibers of the zona externa have been traced. I have not been able to obtain an unambiguous view of any single narrow tangential fiber within the zona externa indisputably both passing into the layer of external somata via the calycal rim and joining the soma of a globuli cell. Nevertheless, all sequential portions of such a course have been clearly viewed enough times as to leave little doubt that this occurs. Fiber bundles from external globuli cell somata have also been observed in a few instances to extend to points on the surface of the zona externa which lie beyond the calycal rim. It remains unclear whether such fi- bers all travel along the external surface to enter the calycal wall at its rim or whether they may enter the zona externa (and give rise to "narrow tangential fibers") at points lying beyond the rim.

Consequently, in consideration of their similarity to and sometimes close association with the comparably oriented fibers of the zona interna; their extension into the pedunculus, of which they form an integral part; and their presumable origin as direct continuations of fibers belonging to the external globuli cell somata, the narrow tangential fibers of the zona externa are concluded to belong to intrinsic globuli cells of the corpus pedunculatum, specifically those whose cell bodies "overflow" the calyces.

\section{DISCUSSION}

\section{Fiber connections and constituents of the calyces}

In sum I have distinguished five fiber classes within the zona externa of the calyces in $P$. americana. Three consist of extrinsic and two of intrinsic fibers (fig. 4). In the interior of the zona externa, fibers from the calycal tracts are typically the most ubiquitously apparent in my preparations, although "radiating fibers" as well as quartet cell branches can also appear conspicuous when met. The perpendicularly and tangentially oriented intrinsic fibers are typically comparatively inconspicuous.

Whereas the constitution and fiber derivation of the zona interna of cockroaches have been correctly understood since the time of Flögel $(1876,1878)$, previous reports concerning the organization and fiber connections of the zona externa have been highly contradictory. Of the five fiber classes distinguished here within this layer, only the class of narrow fibers which pass into it perpendicularly from the zona interna has been recognized and correctly described in previous accounts of cockroaches (see particularly Bretschneider, '13b, '14; Hanström, '28; Sánchez y Sánchez, '33). Scrutiny of the descriptions and figures of Sánchez y Sánchez ('33) reveals in addition that some fibers depicted in Blatta orientalis as "centripetal" with respect to the calyces (fibers here termed "extrinsic") may represent intrinsic tangential fibers of the zona externa. Moreover, figure 5 in the same work includes a 
portion of a fiber (fiber "B, H") which may perhaps correspond to an extrinsic radiating fiber of $P$. americana. Prior studies of cockroach calyces include no hints of quartet cell fibers or calycal tracts and their terminations, although reports that the tractus olfactorio-globularis enters the calyces naturally imply the presence there of terminations of some sort.

Of the two main sets of extrinsic fibers followed in the present work from within the zona externa to regions outside the corpus pedunculatum, the tractus olfactorioglobularis (sensu lato), as indicated above, has been described by Jawlowski ('48, '53) in a form closely resembling that observed here (for a particularly well documented account of a similarly arranged tractus olfactorio-globularis, sensu stricto, in Lepidoptera see Pearson, '71). Apart from the naming by Brousse-Gaury ('68, '71) of a "nucleus" which apparently includes quartet cell somata, and the report of a connection between this and the neruus corporis cardiaci II (see below), previous accounts of cockroaches contain no indication of the existence of the quartet neurons or any fibers attributable to them.

In other insect groups intrinsic fibers comparable to those in cockroaches which pass perpendicularly from zona interna into zona externa are well known (e.g., Hymenoptera: Kenyon, 1896; Hemiptera: Pflugfelder, '36-'37). The presence in these groups of a fiber class homologous with the intrinsic tangential fibers of the zona externa of $P$. americana is discussed elsewhere (Weiss, '70). Although a tractus olfactorio-globularis (sensu stricto) has been widely reported throughout the Pterygota, little is known concerning calycal terminations explicitly attributed to it (Hemiptera: Pflugfelder, '36-37; Formica: Goll, '67; Lepidoptera: Pearson, '71); none of these authors mentions an arrangement of fibers into calycal tracts such as occur in $P$. americana. Extrinsic calycal fibers oriented radially were discovered by Kenyon (1896) in Apis mellifica and have been briefly reported in Orthoptera (Strausfeld, '70). Beyond this similar orientation, insufficient information is available for postulating homologies with the radiating extrinsic fibers described here. The literature dealing with insects other than cockroaches has furnished no indications of neurons seemingly homologous with the quartet cells.

Numerous reports concerning calycal fiber connections in cockroaches, some widely accepted in current publications (e.g., Horridge, '65; Guthrie and Tindall, '68), have not been confirmed in the present study. These reports are summarized below.

Flögel (1878) first described the anterior division of the tractus olfactorio-globularis in a cockroach but was unable to make out its distal course. Consequently, Haller's (05) account of Blatia orientalis contains the first report of a calycal fiber connection in a cockroach. Haller states (pp. 211-212) that just beneath the calyces a portion of the pedunculus carries fibers from one calyx into the other. The support offered is limited to a drawing (fig. 6,B) on which images (of unspecified origin) of these fibers appear to be schematically superimposed.

Bretschneider ('13b, '14) also studied Blatta ("Periplaneta") orientalis. " $\mathrm{He} \mathrm{em}$ ployed Mallory's mixture in connection with other ordinary stains, as well as a gold impregnation method (though apparently without added advantage) (14, p. 271). Horridge's attribution of his findings to Golgi preparations (Horridge, '65, fig. 16.19) is in error.

Bretschneider mentions various fiber connections of the calyces. One, the Riechstrang, is the anterior division of the tractus olfactorio-globularis, as detailed drawings clearly show ('14). The neurons of this tract are reported to belong partly to the deutocerebrum but mostly ( 14, p. 296) to the pars intercerebralis anterior; conversely, the large cells of the pars intercerebralis anterior are said to belong chiefly to this tract (14, p. 291). Evidence for a connection between somata of the pars intercerebralis and fibers within the tract is presented in a drawing ('14, Tafelfig. $F_{2}$ ) which, in my opinion, provides insufficient support for this relationship.

\footnotetext{
6 Text figure 10 of the 1914 work consists of a schematic representation of some neuronal connections of the calyces and other regions in a cockroach brain, "[n] ach Ziegler." This figure derives, however, from neither of Ziegler's cited works, which are his only works known to treat the insect brain. The figure may merely represent the conception which Ziegler, Bretschneider's teacher, held of his student's findings, although it depicts, for example, a cell body (belonging to an optic. calycal connection) whose location was unknown to Bret schneider.
} 
A second calycal connection is with the ipsilateral optic lobe, the location of the somata being unknown. Finally, two connections are described between the calyces and central body, one with somata at the lateral border of the protocerebrum ('14, p. 294) and the other with somata of unknown location ('14, p. 297). As the first of these two tracts passes between the $\alpha$ lobe and calyces, fibers are said to branch off perpendicularly into the calycal walls. Bretschneider may here be describing the anterior division of the tractus olfactorioglobularis as it passes beneath the calyces. Unfortunately, his detailed drawings do not illustrate this section of the anterior division or the reported calycal connections with the central body or optic lobe, although all reported calycal connections but one are shown in a schematic figure. Bretschneider could not confirm Haller's report of a fiber passage between the calyces and considered it incorrect; similarly, Sánchez y Sánchez ('33) failed to see it.

Hanström ('28) briefly mentions two calycal connections of $P$. americana which were examined using Golgi impregnation and vital staining with methylene blue. A "tractus optico-globularis" with large somata in the optic lobe is said to connect it with the calyces. An illustration of the tract is lacking. The tractus olfactorio-globularis (sensu stricto) is said to connect the antennal glomeruli with both central body and calyces and is figured diagrammatically without indication of a lateral continuation beneath the calyces. Hanström was unable to confirm Bretschneider's report that this tract belongs partly to somata in the pars intercerebralis. In turn, Jawlowski (48) subsequently noted the disagreement between Hanström's representation of the tracts of the antennal lobes in $P$. americana and his own observations, a disagreement which includes the tractus olfactorio-globularis.

Arnold ('60) likewise deals with calycal connections in $P$. americana and makes statements which I have not confirmed. These observations have remained unpublished and will not be detailed here.

In a study involving ordinary stains as well as reduced silver (which does not, however, appear to have produced selective fiber impregnation), Drescher ('60) briefly reports observations on the tractus olfac- torio-globularis (sensu stricto) of P. americana. He states that the tract penetrates into the medial calyx and belongs not only to somata lying dorsal to the olfactory lobe but also partly to large somata located under the calyces at the back side of the brain. The tract is shown photographically but evidence is not provided for its relationships.

Willey ('61, p. 235) briefly alludes in an incidental manner to certain fibers with somata in the tritocerebrum which are said to enter the calyces in P. americana.

Barbier ('61), in a study based on ordinary staining methods, attributes three "outside" fiber connections to the calyces of Blatta orientalis. The medial calyx is said to receive a horizontal fiber bundle whose somata lie above the protocerebral lobe and to give off from its own globuli cell somata a vertical bundle which unites it with the central body. In addition, numerous very short fibers believed to arise in calycal globuli cell somata are reported to pass from both calyces into the $\alpha$ lobe. The vertical bundle is represented schematically in Barbier's figure 2 and probably corresponds to a portion of the anterior division of the tractus olfactorio-globularis as well as the initial section of calycal tract 5. Beyond this, evidence substantiating the reported calycal connections is lacking. Although neither remaining connection is explicitly indicated in a figure, the author's figure 8 depicts schematically what could represent the fibers said to pass between calyces and $\alpha$ lobe. My own sections of $P$. americana have sometimes presented images of short segments of sharply impregnated nerve fibers lying between the $\alpha$ lobe and adjacent calycal surface (fig. 51). These fibers have never shown signs of connecting with a calyx but may represent the "very short fibers" which Barbier reports observing here in Blatta.

In a paper on P. americana, Satija and Singla ('67) mention extrinsic fiber connections of the corpora pedunculata. Their study utilized iron haematoxylin, methylene blue (apparently applied to sectioned material), and Holmes' reduced silver method. The illustrations are schematic. No tract is explicitly said to pass into the calyces, but the "antenno-cerebral tract," originating from the antennal lobe ( $p$. 301 ), is implied (p. 298) to connect with 
the corpus pedunculatum, and in the authors' figure 2 this connection is depicted as being with the medial calyx, without indication of a lateral continuation.

In a study, based on non-selective staining methods, of deutocerebral fiber connections in P. americana, Prigent ('68) presents observations on the tractus olfactorio-globularis. During its ascending course this is reported to divide into a "rameau supérieur" and "rameau inférieur." Prigent appears to indicate that the former connects with both calyces and seems to imply that the latter connects with the initial portion of the pedunculus. These two branches of the tractus olfactorioglobularis are depicted schematically in Prigent's figure 1 and indicated in his photomicrograph 6 , although in this photomicrograph I am unable to recognize them as discrete structures relatable to my own observations. The author does not mention any equivalence between his two branches and those earlier described and illustrated by Jawlowski ('48), whose paper he cites.

Finally, Brousse-Gaury (71) describes observations based on reduced silver preparations concerning fibers said to enter the tractus olfactorio-globularis in cockroaches. With reference to $P$. americana, fibers from three sources are reported. One group of neurons, with somata in the ocellar center of the anterior pars intercerebralis, is indicated to send axons into the tractus olfactorio-globularis, directed downwards. A second group, with somata in the posterior pars intercerebralis, is reported to send axons into the nervus corporis cardiaci II and dendrites into the tractus olfactorio-globularis, directed downwards. A third group, with somata also within the pars intercerebralis, is indicated (fig. 94) to send into this tract fibers which bifurcate and send a branch in each direction. While none of these three neuronal types is stated to send fibers into the calyces, Brousse-Gaury does remark that the third group might correspond to neuron type 16 of Bretschneider ('14), which was supposed to represent a calycal connection. In my opinion the evidence for these fiber passages into the tractus olfactorio-globularis is insufficiently convincing.

Brousse-Gaury's ('68) earlier report on Blabera fusca and P. americana, also based on reduced silver impregnation, includes mention and an illustration of a ventroposterior area of the optic lobe from which fibers are said to enter the nervus corporis cardiaci II. The drawings of this "nucleus" ("noyau inféro-postérieur du lobe optique") in B. fusca in Brousse-Gaury's later (71) work, in which this fiber course is again reported, virtually convince me that the nucleus corresponds to or at least includes the quartet neuron somata (note particularly her fig. 36). But its stated emission of fibers into the nervus corporis cardiaci II, for which critical evidence is lacking, does not agree with the branching pattern of the quartet neurons as determined here.

The above reports are typical of literature concerning fiber connections in the insect brain. Rarely do the preparations studied allow visualization of the dispersion of fibers into the regions they are reported to connect, and it is apparently common for authors to report as "connections" tracts seen to contact but not actually verified to enter structures. The habits of illustrating "connections" in schematic figures, and of omitting detailed descriptions, then minimize the ability of later workers to repeat observations and potentially disprove them. The result of these practices has been an accumulation in different insect groups of contradictory reports which may bear little relation to reality.

How complete are the present observations? It seems unlikely that at least hints of any coherent fiber group of appreciable size which enters the calyces would have escaped detection. Scattered entering fibers, however, could perhaps have been missed; especially the calycal area immediately behind the pedunculus deserves further examination for this possibility, for here one or two fibers of uncertain origin have been observed. If the extrinsic "radiating fibers" of the zona externa do not stem from the tractus olfactorio-globularis (sensu lato) then they probably derive from fairly narrow fibers which pass into the calyces in a dispersed manner.

The conclusion reached above that the calycal tract fibers derive exclusively, or almost exclusively, from the divisions of the tractus olfactorio-globularis does not necessarily imply that they all synapse in the antennal lobe. First, the origin of the posterior division remains to be established 
conclusively. Secondly, although the anterior division (i.e., tractus olfactorio-globularis in its usual usage) has repeatedly been reported in different groups to ascend from the antennal lobe, it may well receive some fibers from other regions. Jawlowski ('53), for example, has reported that two small fiber bundles extending respectively out of the tritocerebrum and subesophageal ganglion become included in the divisions of the tractus olfactorio-globularis in $P$. americana. Still, the widely reported ventral connection with the antennal lobe can be accepted for at least the bulk of the anterior division, and this implies that in $P$. americana calycal fibers extending from the antennal lobe (or perhaps from both of them: see Hanström, '28; Jawlowski, '53) far outnumber extrinsic calycal fibers from any other single source and probably comprise the preponderant majority of extrinsic fibers in the calyces. Corresponding well to this conclusion is the finding from ultrastructural study (Weiss, unpublished) that most extrinsic calycal fibers belong to a single class which derives from calycal tracts.

\section{Functional implications}

Despite over a century of interest, the role of insect corpora pedunculata remains unclear. Traditionally these structures have been regarded as "higher centers," centers of sensory association, "the seat of complex behavior," and so forth. These views originated in anatomical studies, particularly of the massive, complex corpora pedunculata of some Hymenoptera. Although recent experimental studies have yielded many interesting observations, I believe with Howse and Williams ('69) that they have failed to provide an incisive explanation of the special role of the corpora pedunculata. Representative of the varied experimental approaches employed are papers by Maynard ('56, '67), Voskresenskaya ('57), Burtt and Catton ('59), Drescher ('60), Rowell ('63), Huber (several works, mostly reviewed in Huber, '65), Horridge, Scholes, Shaw and Tunstall ('65), Dingle and Fox ('66), Vowles ('67 and earlier works), Steiner and Pieri ('69), Bernstein and Bernstein ('69), Otto ('71), and Turanskaya ("72).

The corpora pedunculata of $P$. americana, while large, are more typical of pter- ygotes than are the highly elaborated centers of some Hymenoptera, and their study can accordingly provide a proper perspective. The present findings do in fact suggest a way of looking at these centers which may prove fruitful.

Studies entailing electrical stimulation of the corpora pedunculata in various insects have demonstrated that different behavioral acts start or stop following stimulation. Yet significantly, there is a lack of experimental evidence that any particular segments of the behavioral repertoire are uniquely associated with the corpora pedunculata throughout the insects. Moreover, despite the impressive elaboration of the corpora pedunculata in some social insects, comparisons within the full range of other insects does not suggest any consistent correlation between the nature or complexity of the overt behavioral repertoire and the degree of development of these brain centers. Thus the special significance of the corpora pedunculata may not relate to their output at all. Then it would not be surprising that complete extirpation of all four calyces and their cell bodies in P. americana has so little obvious effect on motor capabilities (Drescher, '60).

If the special role of the corpora pedunculata does not concern their output, might it concern their input and its processing? What is the nature of this input? So many tracts have been claimed to connect the calyces with other brain regions in different insects that one prevalent notion regards the corpora pedunculata as the paramount collectors and integrators of information from throughout the brain. Another view, advocated notably by Han ström (e.g., '28, '40), maintains that in the original as well as most present-day pterygotes the corpora pedunculata serve primarily to combine optic with antennal information. A very few authors, however, have noticed a particular comparative anatomical relationship between antennal input and the size of corpora pedunculata or their calycal region (Pflugfelder, '36-'37; Jawlowski, '63; Prigent, '68; see also Howse and Williams, '69). Jawlowski especially has emphasized the dependence of the level of calycal development on the degree of development of the antennal lobes but not compound eyes. My own observations pro- 
vide immediate support for the view that antennal but not optic input is all-important to the corpora pedunculata, and they suggest that the corpora pedunculata of pterygotes are fundamentally second-order antennal sensory processing centers.

The anatomical literature offers widespread evidence in pterygotes for an insistent dependence of the calycal region on the antennal lobes. The first three of the authors just cited provide examples. In an extensive examination of the literature for each order since 1850, I have found no case in which a moderately developed calycal region occurs simultaneously with rudimentary antennal lobes. Moreover, it appears that wherever the calycal region attains its most prominent development, as in some cockroaches, acridid grasshoppers, and hymenopterans, unquestionably welldeveloped antennal lobes are invariably present (note their prominence, for example, in fig. 5).

The literature does not appear to hold evidence for a similar dependency of the calycal region on any other central nervous structure or sense organ, including the optic lobes or compound eyes. It is noteworthy that instances are available from widely different orders in which a fully developed calycal region occurs in a species or caste simultaneously with extremely reduced compound eyes (ants: Pandazis, '30; termites: Hecker, '66; a blind species of the apterygote group Lepismatidae: Hanström, '40); thus the combination of optic with antennal information could hardly be the primary task of the corpora pedunculata. Although tracts have frequently been reported to connect the optic lobe and calycal region in various pterygotes, little substantiation for these claims has ever been offered. Such connections may occur in those Hymenoptera with highly developed corpora pedunculata, where their existence has been reported by workers successfully applying silver impregnation methods. But in other pterygotes, none of the few authors who have obtained demonstrable success with specific neurological methods reports finding a tract connecting the optic lobe and calycal region, although Hanström (28), who used specific methods on $P$. americana, states without substantiation that such a tract occurs in this species. The closest thing to such a connection to receive substantiation by these authors is described by Pearson ('71) in the butterfly Pieris brassicae: here she found a tract which extends into the calyx and is said to arise not in the optic lobe but in an area of the protocerebrum in which optic fibers end. In the moth Sphinx ligustri she found corresponding fibers but no definite tract. In the lepidopterans which she studied she believed the visual input into the calyx to be probably less than one quarter as large as the antennal input. On the basis of his own observations in different orders, albeit founded on the use of iron haematoxylin, Jawlowski ('63) too has questioned the occurrence, except in some Hymenoptera, of distinct, well-differentiated optic-calycal connections.

A distal continuation of the tractus olfactorio-globularis (sensu stricto) lateral to the pedunculus, such as occurs in P. americana, is known in several other orders (e.g., Power, '46; Jawlowski, '53, '63; Pearson, '71). I suspect that the widely mentioned "tractus optico-globularis" of Hanström, or at least certain tracts given this name by later authors, may actually represent nothing more than this distal continuation (cf. Power, '46).

Certainly, even outside the Hymenoptera, the calycal region may receive strong non-antennal input. Perhaps an increased processing of such input is ordinarily tied to the elaboration of accessory calycal neuropiles: thus in Orthoptera, a thick tract believed to derive from the tritocerebrum connects with the substantial accessory calyx (Jawlowski, '53). Evidence may indeed eventually appear in groups outside the Hymenoptera for direct optic lobe-calyx connections. But in any case comparative anatomy shows that throughout the pterygotes the calycal region has remained overridingly dependent on antennal input, implying that its role as a processor of antennal information has remained predominant.

Whether the size of the entire corpus pedunculatum is as obligately dependent on antennal input as is the size of the calycal region is presently unclear, although there does seem to be some dependency. Perhaps in addition to the neurologically complex role of processing information, the corpus pedunculatum serves some simpler role such as supplying tonic neural output, a 
role which would remain when the calycal region, with its informational processing function, is reduced.

In sum, I suggest that attempts to understand the corpora pedunculata principally in terms of the nature of their output may be basically misdirected. Probably they serve as only two of many sources of "instructions" which ultimately influence motor behavior. What seems to distinguish these centers is that their instructions derive principally from analysis of antennal information. Indeed their significance for the higher-level processing of antennal information may compare to that of the medulla interna and medulla externa of the optic lobe for the higher-level processing of optic information. But what the relative importance of different sensory modalities such as olfaction and mechanoreception may be in their input, remains to be learned.

In a discussion of the corpora pedunculata of Hymenoptera, Horridge ('65, p. 1244) has suggested that the calyces are hemispherical charts onto which antennal and optic information is spatially projected. While my observations cannot strictly exclude such a mapping of antennal information in $P$. americana, they provide no visible support for it, unless the comparatively few "radiating fibers" should turn out to represent an ordered antennal input. The possibility is open, then, that widely branching fibers from the tractus olfactorio-globularis (sensu lato) provide an essentially identical combination of input over each entire calyx or at least within large areas. Still, at every given locus, different dendritic trees of the globuli cells (which number some $2 \times 10^{5}:$ Neder, '59) would be expected to experience numerous subtly different combinations of input from the extrinsic fibers, whose parent neurons number in the hundreds. We may speculate that globuli-cell dendritic trees happening to be responsive to identical combinations of input might at any one instant be found scattered statistically over the calycal wall, or at least over large areas within it; responsiveness would presumably depend on both physiological state and anatomical conditions, either of which might have been modified by developmental changes, importantly including any related to "learning." We can then imagine that particular stim- uli patterns, notably those of biological importance, would evoke a response in the dendritic trees of an appropriate, statistically scattered collection of globuli cells, and that it is a statistical average of the particular temporal and spatial distribution of firing axons across a cross-section of the $\alpha$ and $\beta$ lobes which evokes the appropriate postsynaptic response in the extrinsic fibers of these lobes. Interestingly, in my reduced silver preparations of $P$. americana the comparatively few extrinsic neurons of the $\alpha$ and $\beta$ lobes do indeed seem arranged so as to sum activity over a wide cross-sectional area of the lobes.

Yamada's ('71) recent study of extracellularly recorded responses to odors in single fibers of the antennal lobe of $P$. americana bears directly on these ideas. This author concludes that odor encoding at the level of the antennal lobe may involve a "unique across-lobe pattern of discharges ('odour code pattern') for each particular odorant." Since many or even most of Yamada's recordings were presumably from originating tractus olfactorio-globularis fibers his conclusion would almost necessarily imply, for each particular odorant, a unique "across-tract" discharge pattern within one or both divisions of the tractus olfactorio-globularis. While olfactory information undoubtedly constitutes only one component of the antennal input into the calyces, it is nevertheless unique multifiber input patterns of precisely this kind to which I suggest appropriate sets of globuli cells are responsive, and which I suggest the corpora pedunculata can thus discriminate. It is most important that electrophysiological work along these lines be continued, and that responses to various natural stimuli be followed in to the calyces and ultimately to the extrinsic fibers which leave the $\alpha$ and $\beta$ lobes.

\section{ACKNOWLEDGMENTS}

I am indebi zd to Dr. Richard D. Alexander for his p.ttience and encouragement throughout the course of this study. I would like to thank him and Drs. Bruce Oakley, John S. Edwards, and R. K. Murphey for valuable comments on various drafts of the manuscript. The final drawings were carefully prepared by Mrs. Carol C. Jerome.

The study was aided by Graduate Fel- 
lowships from the National Science Foundation. Preparation of the manuscript was supported at the University of Washington by Postdoctoral Research Fellowships from the National Institute of Neurological Diseases and Stroke.

\section{LITERATURE CITED}

Arnold, W. J. 1960 The anatomy of the cephalic nervous system of the cockroach, Periplaneta americana (L.), with histological and histochemical studies of the brain. Ph.D. Thesis, University of California, Berkeley, $81 \mathrm{pp}$.

1964 Structural organization in the neuropile of the Periploneta brain. J. Cell Biol., 23 : $6 \mathrm{~A}$ (abstract).

Barbier, R. 1961 Contribution à l'êtude des centres cérébröides chez les Insectes. Les corps pédonculés et le corps central de la Blatte, Blatta (Periplaneta) orientalis. Bull. Soc. Zool. Fr., 86: $737-753$.

Bernstein, S., and R. A. Bernstein 1969 Relationships between foraging efficiency and the size of the head and component brain and sensory structures in the red wood ant. Brain Res., 16: 85104.

Bodian, D. 1937 The staining of paraffin sections of nervous tissues with activated protargol. The role of fixatives. Anat. Rec., 69: 153-162.

Bretschneider, F. $1913 \mathrm{a}$ Uber das Gehirn und das Gedächtnis der Küchenschabe. Naturw. Wochschr., N.F., 12; 154-156.

- 1913b Der Centralkörper und die pilzförmigen Körper im Gehirn der Insekten. Zool. Anz., $41: 560-569$.

- 1914 Über die Gehirne der Küchenschabe und des Mehlkäfers. Jena. Z. Naturw., 52: 269362.

Brousse-Gaury, P. 1968 Localisation des noyauxorigines des nerf's paracardiaques, de Dictyoptères Blaberidate et Blattidat. C. R. Hebd. Séanc. Acad. Sci., Paris (D), 266: 1972-1975.

1971 Influence de stimuli externes sur le comportement neuro-endocrinien de Blattes. I. Les organes sensoriels céphaliques, point de départ de réflexes neuro-endocriniens. II. Histophysiologie des voies réflexes neuro-endocriniennes. Ann. Sci. Nat., Zool., (12) 13; 181-450.

Bullock, T. H., and G. A. Horridge 1965 Structure and Function in the Nervous Systems of Invertebrates. W. H. Freeman and Company, San Francisco and London, 2 vols.

Burtt, E. T., and W. T. Catton 1959 Transmission of visual responses in the nervous system of the locust. J. Physiol., Lond., 146; 492-515.

Chen, J. S., and R. Levi-Montalcini 1970 Long term cultures of dissociated nerve cells from the embryonic nervous system of the cockroach Periplaneta americana. Arch. Ital. Biol., 108: 503537.

Day, M. F. 1950 The histology of a very large insect, Macropanesthia rhinocents Sauss. (Blattidae). Aust. J. Scient. Res., Ser. B, 3: 61-75.

Dingle, H., and S. S. Fox 1966 Microelectrode analysis of light responses in the brain of the cricket (Gryllus domesticus). J. Cell. Physiol., 68: 45-59.
Drescher, W. 1960 Regenerationsversuche am Gehirne von Periplaneta americana unter Berücksichtigung von Verhaltensänderung und Neurosekretion. Z. Morph. Ökol. Tiere, 48: 576649 .

Dujardin, F. 1850 Mémoire sur le système nerveux des Insectes. Ann. Sci. Nat, Zool., (3) 14: 195-206.

Flögel, J. H. L. 1876 Ueber den feineren Bau des Arthropodengchirns. Tageblatt der 49. Versamm lung deutscher Naturforscher und Aerzte, Beilage, pp. 115-120.

1878 Ueber den einheitlichen Bau des Gehirns in den verschiedenen Insecten-Ordnungen. Z. wiss. Zool., Suppl., 30: 556-592.

Frontali, N. 1968 Histochemical localization of catecholamines in the brain of normal and drugtreated cockroaches. J. Insect Physiol., 14: 881886.

1971a On the organization of the corpora pedunculata: a histochemical and untrastructural [ultrastructural] study. Proc. XIII Intern. Congr. Ent., Moscow, 1968, Vol. I, pp. 244-245.

$1971 \mathrm{~b}$ On the organization of the corpora pedunculata: a histochemical and ultrastructural study. Proc. XIII Intern. Congr. Ent., Moscow, 1968, vol. I, p. 377.

Frontali, N., and G. Mancini 1970 Studies on the neuronal organization of cockroach corpora pedunculata. J. Insect Physiol., 16: 2293-2301.

Frontali, N., and K.-A. Norberg 1966 Catecholamine containing neurons in the cockroach brain. Acta Physiol. Scand., 66: 243-244.

Frontali, N., R. Piazza and R. Scopelliti 1971 Localization of acetyl-cholinesterase in the brain of Periplaneta americana. J. Insect Physiol., 17: 1833-1842.

Frontali, N., and R. Pierantoni 1973 Autoradiographic localization of ${ }^{3} \mathrm{H}-\mathrm{GABA}$ in the cockroach brain. Comp. Biochem. Physiol., 44A: 13691372.

Goll, W. 1967 Strukturuntersuchungen am Gehirn von Formica. Z. Morph. Ökol. Tiere, 59: 143-210.

Gouin, F. J. 1965 Morphologie, Histologie und Entwicklungsgeschichte der Myriapoden und Insekten. III. Das Nervensystem und die neurocrinen Systeme. Fortschr. Zool., 17: 189-237.

Guthrie, D. M., and A. R. Tindall 1968 The Biology of the Cockroach. St. Martin's Press, New York.

Haller, B. 1905 Über den allgemeinen Bauplan des Tracheatensyncerebrums. Arch. mikrosk. Anat., 65: 181-279.

Hanström, B. 1928 Vergleichende Anatomie des Nervensystems der wirbellosen Tiere unter Berücksichtigung seiner Funktion. J. Springer, Berlin.

1940 Inkretorische Organe, Sinnesorgane und Nervensystem des Kopfes einiger niederen Insektenordnungen. K. Svenska VetenskAkad. Handl., (3) 18(8): 1-266.

Hecker, H. 1966 Das Zentralnervensystem des Kopfes und seine postembryonale Entwicklung bei Bellicositermes bellicosus (Smeath.) (Isoptera). Acta Trop., 23: 297-352.

Hess, A. 1972 Histochemical localization of cholinesterase in the brain of the cockroach (Pcriplanet( americana). Brain Res., 46: 287-295. 
Holmgren, N. 1909 Termitenstudien I. Anatomische Untersuchungen. K. Svenska VetenskAkad. Handl., 44(3): 1-215.

Holste, G. 1923 Das Gehirn von Dytiscus marginalis L. Z. wiss. Zool., 120: 251-280.

Horridge, G. A. 1965 The Arthropoda, Part III. In: Structure and Function in the Nervous Systems of Invertebrates. T. H. Bullock and G. A. Horridge, eds. W. H. Freeman and Company, San Francisco and London, pp. 801-1270.

Horridge, G. A., J. H. Scholes, S. Shaw and J. Tunstall 1965 Extracellular recordings from single neurones in the optic lobe and brain of the locust. In: The Physiology of the Insect Central Nervous System. J. E. Treherne and J. W. L. Beament, eds. Academic Press, London and New York, pp. 165-202.

Howse, P. E., and J. L. D. Williams 1969 The brains of social insects in relation to behaviour. Proc. VI Congr. Intern. Union for the Study of Social Insects, Bern, pp. 59-64.

Huber, F. 1965 Neural integration (central nervous system). In: The Physiology of Insecta. M. Rockstein, ed. Academic Press, New York and London, Vol. II, pp. 333-406.

Jawlowski, H. 1948 Studies on the insects brain. Ann. Univ. Mariae Curie-Skłodowska, Lublin (C), 3: $1-37$.

3. 1-3953 Über die Struktur des Gehirnes bei Saltatoria. Ann. Univ. Mariae Curie-Sklodowska, Lublin (C), 8: 403-434.

1963 On the origin of corpora pedunculata and the structure of the tuberculum opticum (Insecta). Acta Anat., 53: 346-359.

Kenyon, F. C. 1896 The brain of the bee. A preliminary contribution to the morphology of the nervous system of the Arthropoda. J. Comp Neur., 6: 133-210.

Khan, T. R. 1962 Histological studies on the brain and retrocerebral complex of the cockroaches, Periplaneta americana $\mathrm{L}$. and Blatta orientalis L. (Dictyoptera : Blattaria : Blattidae). Ph.D. Thesis, University of Glasgow, pp. iii $+222$.

Khan, T. R., and A. Fraser 1962 Neurosecretion in the embryo and later stages of the cockroach (Periplaneta americanit L.). In: Neurosecretion. Mem. Soc. Endocr., No. 12. H. Heller and R. B. Clark, eds. Academic Press, London and New York, pp. 349-369.

Levi-Montalcini, R., and J. S. Chen 1969 In vitro studies of the insect embryonic nervous system. In: Cellular Dynamics of the Neuron. Symp. Intern. Soc. Cell Biol., Vol. 8. S. H. Barondes, ed. Academic Press, New York and London, pp. 277-298.

Lhoste, J, and A. Roche 1956 Action de l'heptachlore sur les ganglions cérébröides de la blat te Blabert fusca Br. Arch. Anat. Microsc. Morph. Exp., 45: 302-310.

Malzacher, P. 1968 Die Embryogenese des Gehirns paurometaboler Insekten. Untersuchungen an Carausias morosus und Periplaneta americana. Z. Morph. Tiere, 62: 103-161.

Mancini, G., and N. Frontali 1967 Fine structure of the mushroom body neuropile of the brain of the roach, Periplaneta americana. Z. Zellforsch. mikrosk. Anat., 83: 334-343.

__ 1968 On the ultrastructural localization of catecholamines in the brain of the cockroach,
Periplaneta americana. In: Electron Microscopy: 1968. Pre-Congr. Abstr. Fourth Europ. Reg. Conf, Rome. Vol. II. D. S. Bocciarelli, ed. Tipografia Poliglotta Vaticana, Rome, pp. 543-544.

1970 On the ultrastructural localization of catecholamines in the beta lobes (corpora pedunculata) of Periplaneta americana. Z. Zellforsch. mikrosk. Anat, 103: 341-350.

Maynard, D. M. 1956 Electrical activity in the cockroach cerebrum. Nature, Lond., 177: 529 530 .

- 1967 Organization of central ganglia. In: Invertebrate Nervous Systems: Their Significance for Mammalian Neurophysiology. C. A. G. Wiersma, ed. The Univ. of Chicago Press, Chicago and London, pp. 231-255.

Neder, R. 1959 Allometrisches Wachstum von Hirnteilen bei drei verschieden grossen Schabenarten. Zool. Jahrb,, Anat., 77: 411-464.

Newton, E. T. 1879 On the brain of the cockroach, Blatta onientalis. Quart. J. Microsc. Sci., N.S., $19: 340-356$.

Otto, D. 1971 Untersuchungen zur zentralnervösen Kontrolle der Lauterzeugung von Grillen. Z. vergl. Physiol., 74: 227-271.

Pandazis, G. 1930 Úber die relative Ausbildung der Gehirnzentren bei biologisch verschiedenen Ameisenarten. Z. Morph. Ökol. Tiere, 18: 114169.

Panov, A. A. 1957 Bau des Insektengehims während der postembryonalen Entwicklung. Éntomologich. Obozr., 36: 269-284. (In Russian, with German summary.)

Pearson, L. 1971 The corpora pedunculata of Sphinx ligustri L. and other Lepidoptera: an anatomical study. Phil. Trans. Roy. Soc. Lond., B, 259: 477-516.

Ptlugfelder, O. 1936-1937 Vergleichend-anatomische, experimentelle und embryologische Untersuchungen über das Nervensystem und die Sinnesorgane der Rhynchoten. Zoologica, Stuttgart, 34(93): 1-102.

Power, M. E. 1946 The antennal centers and their connections within the brain of Drosophilat melanogaster. J. Comp. Neur., 85: 485-517.

Prigent, J.-P. 1968 Les connexions du deutocerebron de l'adulte de Periplaneta americana L, Bull. Soc. Zool. Fr., 93: 149-157.

Ratzerdorfer, C. 1952 Volumetric indices for the parts of the insect brain. A comparative study in cerebralization of insects. J. New York Ent. Soc., 60: 129-152.

Rowell, C. H. F. 1963 A method for chronically implanting stimulating electrodes into the brains of locusts, and some results of stimulation. J. Exp. Biol., 40: 271-284.

Sánchez y Sánchez, D. $1933^{7}$ Contribution à la connaissance de la structure des corps fongiformes (calices) et de leurs pedicules chez la blatte commune (Stylopyga (Blatta) orientalis). Trab. Lab. Invest. Biol. Univ. Madrid, 28: 149185.

${ }^{7}$ The following virtually unknown work, of which a copy was obtained through the kindness of Prof. Dr. A. Carrato Ibáñez of the Instituto Cajal, is merely a Spanish translation of Sánchez y Sánchez's 1933 paper: Sánchez y Sánchez, D. 1937 Datos para el conocimiento de la estructura de los cuerpos fungiformes (cálices) y sus pediculos en la cucaracha común (Stylopyga (Blatta) orientalis L.). Arch. Neurobiol., 16 (1-2): 1-37. 
Satija, R. C., and O. P. Singla 1967 Structure of the brain of Periplaneta americana L. (Dictyoptera). Res. Bull. (N.S.) Panjab Univ., 18: 297302.

Shao, Y. Y., and S. E. Dixon 1964 Hydrolyzing enzyme activity in the brain and the retroccrebral system of the American cockroach (Pcriplaneta americana (L)) with special reference to the neurosecretory materials. Can. J. Zool., 42 : 281-293.

Steiner, F. A., and L. Pieri 1969 Comparative microelectrophoretic studies of invertcbrate and vertebrate neurones. In: Mechanisms of Synaptic Transmission. Prog. Brain Res, Vol. 31. K. Akert and P. G. Waser, eds. Elsevier Publ. Co., Amsterdam, London, and New York, pp. 191199.

Strausfeld, N. J. 1970 Variations and invariants of cell arrangements in the nervous systems of insects. (A rcview of neuronal arrangements in the visual system and corpora pedunculata). Verh. Disch. Zool, Ges., 64. Tag, pp, 97-108.

Turanskaya, V. M. 1972 The role of corpora pedunculata in conditional reflexes of honey bees. (In Ukrainian, with English summary.) Dopov. Akad. Nauk Ukr. RSR, B, 1972: 562564 .

Voskresenskaya, A. K. 1957 On the role played by the fungoid bodies of the supraesophageal ganglion in conditioned reflexes of the honeybee. Dokl. Akad. Nauk SSSR (Biol. Sci. Sect. Transl.). 112: 166-169.

Vowles, D. M. 1955 The structure and connex- ions of the corpora pedunculata in bees and ants. Quart. J. Microsc. Sci., 96: 239-255.

1967 Interocular transfer, brain lesions. and maze learning in the wood ant, Formict rufa. In: Chemistry of Learning. W. C. Corning and S. C. Ratner, eds. Plenum Press, New York, pp. $425-447$.

Weiss, M. J. 1970 Structure and fiber connections of the calyces in the brain of the American cockroach, Periplaneta americana (L.), with comparative observations on an acridid grasshopper, Melanoplus femur-rubrum $f$. $r$. (DeGeer). Ph.D. Dissertation, University of Michigan, pp. $\mathrm{vi}+182$. No. 71-4768, University Microfilms, Inc., Ann Arbor, Mich., U.S.A. Dissert. Abstr. Intern., 31: 5085-B.

1971 From soma to synapse: the tracing of fiber inputs of a complex brain center in the American cockroach, Periplaneta americana (L.). Am. Zool., 11:696-697 (abstract).

1972 a A reduced silver staining method applicable to dense neuropiles, neuroendocrine organs, and other structures in insects. Brain Res., 39: 268-273.

1972b "Growth rings" and their evolution in the brain of insects. Am. Zool., 12: 717718 (abstract).

Willey, R. B. 1961 The morphology of the stomodeal nervous system in Periplaneta americuna (L.) and other Blattaria. J. Morph., 108: 219-261.

Yamada, M. 1971 A search for odour encoding in the olfactory lobe. J. Physiol., Lond., 214: $127-143$. 
All photomicrographs are from $10-\mu$ sections of the brain of adult male $P$. americana, prepared as indicated in MATERIALS AND METHODS. Unless otherwise noted, in each photograph stated to represent either a frontal, transverse, or sagittal section, it will respectively hold true that dorsal will be upwards, anterior will be upwards, or anterior will be to the left.

\section{PLATE 1}

\section{EXPLANATION OF FIGURES}

5 Frontal view of brain (cf. fig. 1). Note the dorsal calyces, whose concavities are filled with innumerable globuli cell somata; the massive $\beta$ lobes, adjoining in the midline just beneath the central body; and, situated ventrally, the large glomeruli-filled antennal sensory lobes, each connected laterally with its correspondingly large nerve. The section is located anterior to the optic lobes and to the connection of each pedunculus with its pair of calyces. Approximately $\times 57$.

6 Sagittal view of brain. The calyces are sectioned in the region of their apposed vertical walls. Note the pedunculus, which descends from the calyces above the center of the picture, and the massive $\alpha$ lobe, which ascends vertically, near the front of the brain, from the lower end of the pedunculus. Below the $\alpha$ lobe several glomeruli of the antennal sensory lobe are apparent. $\times 87$.

7 Frontal view of lower wall of medial calyx. The two layers of the calycal wall are clearly visible: the zona interna (zi), adjacent to the somatafilled cavity of the calyx and in one region seen to be receiving fiber bundles from these somata; and the zona externa (ze), along the external surface of which the layer of globuli cell somata can be seen to extend downward for some distance. $\times 350$.

8 Frontal view of a small portion of lower wall of medial caly $x$, with globuli cell somata of the calycal concavity seen at upper right. Arrows indicate some of the narrow fibers or fiber bundles which pass perpendicularly from the zona interna in to the zona externa. $\times 900$. 

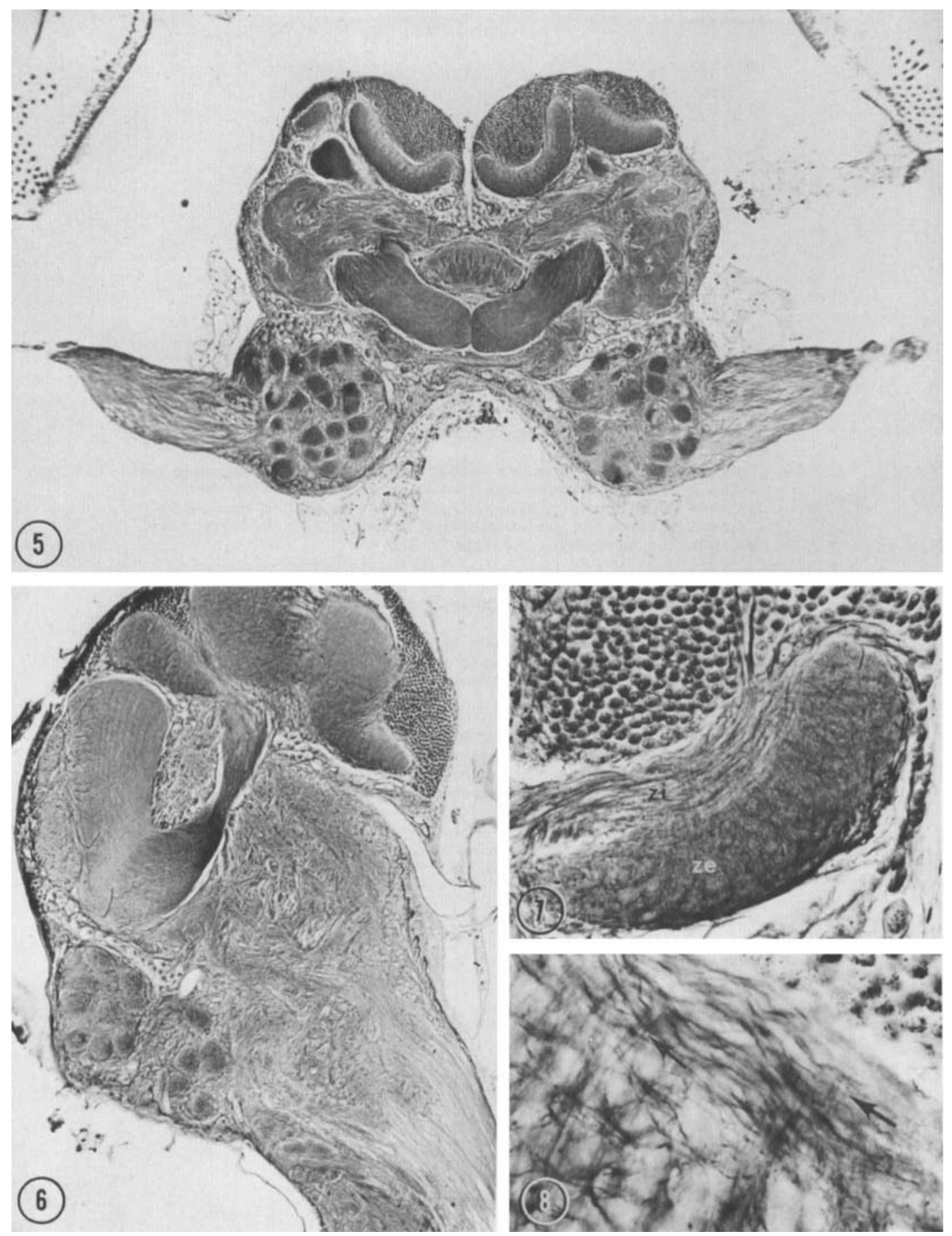
PLATE 2

EXPLANATION OF FIGURES

9 Frontal view of a section just glancing posteriorly the connection between optic lobe (upper left) and brain. The arrow points to the four large cell bodies of the quartet neurons. $\times 87$.

10 Transverse view of posterior border of protocerebrum, showing cell bodies of quartet neurons (the two large cell bodies with prominent nucleoli below center of picture) as well as two quartet neuron fibers (arrows) just entering the protocerebral neuropile from the cortical layer of cell bodies. Medial is to the right. $\times 350$.

11 Frontal view showing the fibers of the four quartet neurons while still within the layer of cell bodies (arrows). Medial is to the right. $\times 350$.

12 Frontal view showing the fibers of the quartet neurons sectioned in region 1 , not far from the point of entrance in to the protocerebral neuropile (the four large fibers arranged in a row in center of picture). Medial is to the left. $\times 900$.

13 Frontal view. The branch 2's (upper arrow) and fiber 1's (lower arrow) of the quartet neurons are sectioned just posterior to their junction. Note the origin and presence of two columns in the pedunculus of the corpus pedunculatum. The field shown in figure 40 is included within this photograph. $\times 87$.

14 Frontal view showing main branching region of the quartet neurons, with the various branches labeled (cf. fig. 2). Medial is to the right. $\times 350$. 

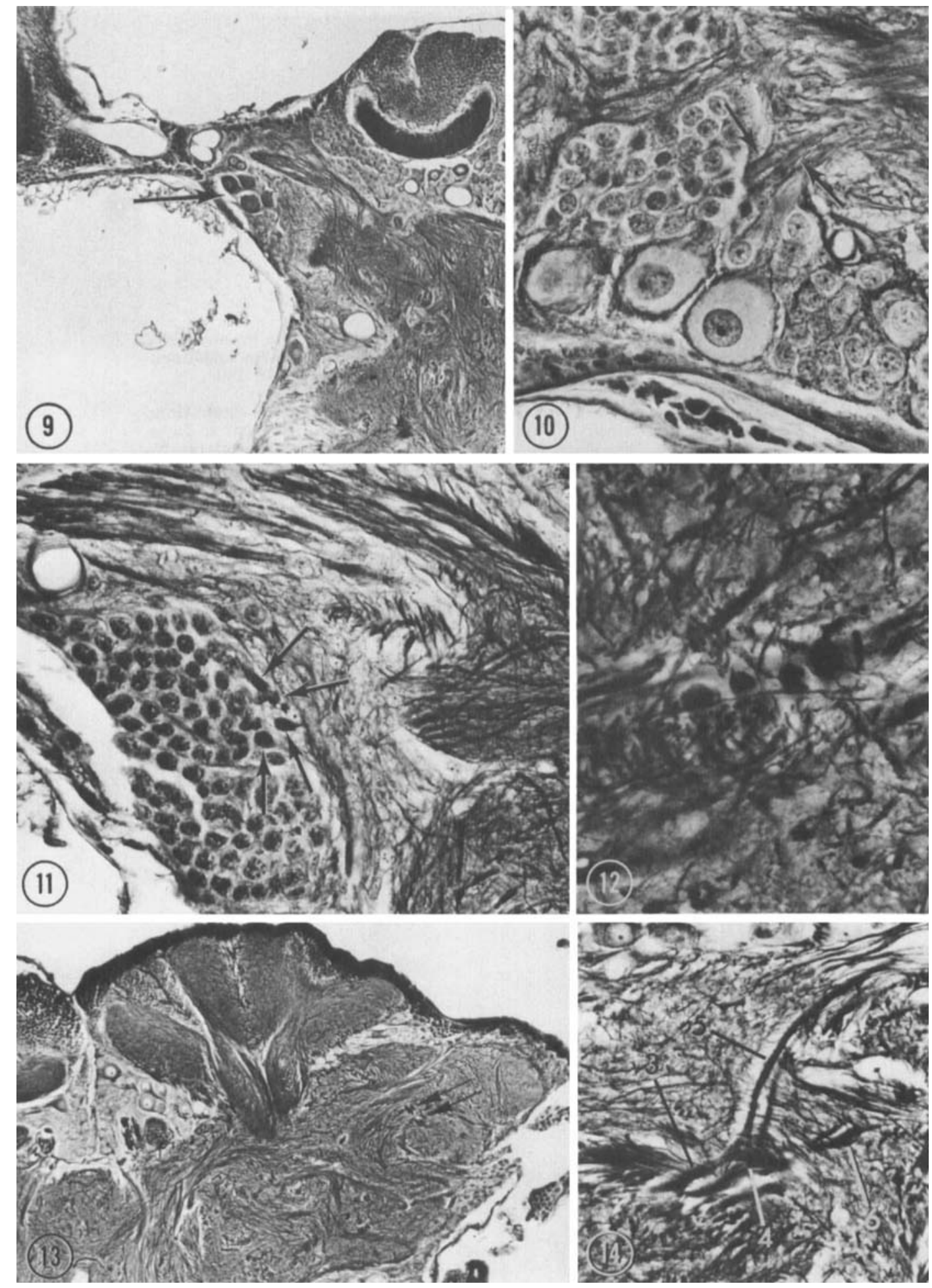


\section{PLATE 3}

EXPLANATION OF FIGURES

15 Frontal view showing passage of the four large, parallel branch 5's of the quartet neurons into the in tercalycal region of the corpus pedunculatum (just above center of picture). Medial is to the left. $\times 350$.

16 Frontal view of lower wall of lateral calyx. Medial is to the right. Along the external margin of the zona externa are seen, from left to right, calycal tract $2 \mathrm{~b}$ (black arrows), two large representatives of the $5 \mathrm{~A}$ branches of the quartet neurons (white arrows), and calycal tract 3 (black arrows). $\times 350$.

17 Frontal view of the apposed vertical walls of the two calyces of a corpus pedunculatum. The fiber indicated by the arrow and three large, similarly oriented fibers immediately below it represent the four $5 \mathrm{~B}$ branches of the quartet neurons. Medial is to the right. Approximately $\times 440$. In set: Frontal view of the four $5 \mathrm{C}$ branches of the quartet neurons, sectioned not far from their origin. Note the significant range in size. Medial is to the left. $\times 900$.

18 Frontal view of lower wall of lateral calyx. The large, darkly stained fiber within the zona externa, just below the center of the picture, is traceable to the branch 6 of a quartet neuron. Medial is to the right. $\times 350$.

19 The 5B branch of a quartet neuron with a typical example of a nucleuslike body embedded within it (arrow), $\times 1700$.

20 Frontal view showing the ascent of the anterior division of the tractus olfactorio-globularis (arrow) to the level of the medial calyx. The lamellated nature of the pedunculus is apparent at the right edge of the picture. The black line indicates the approximate plane of section of figure 21. $\times 87$. 

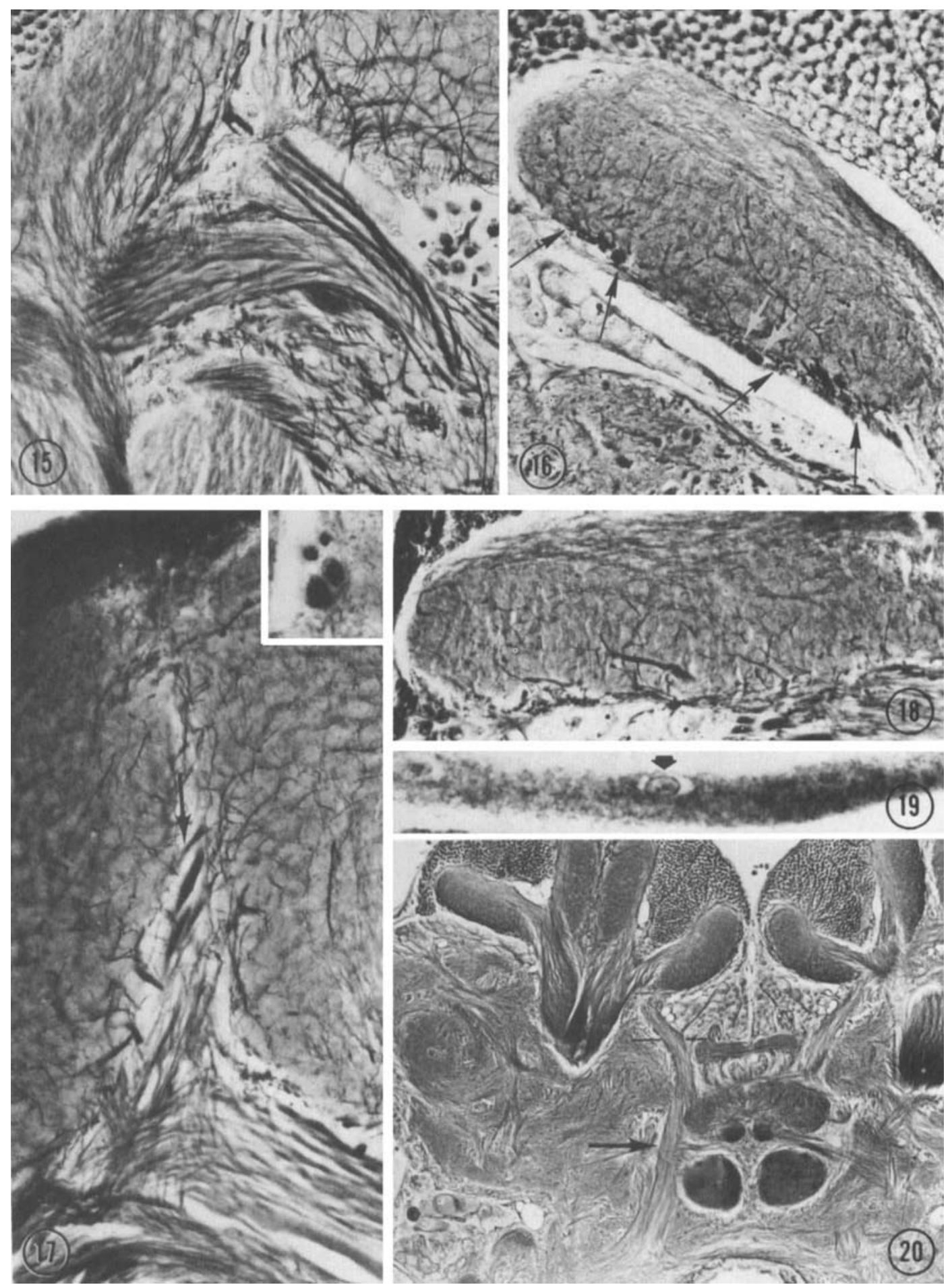


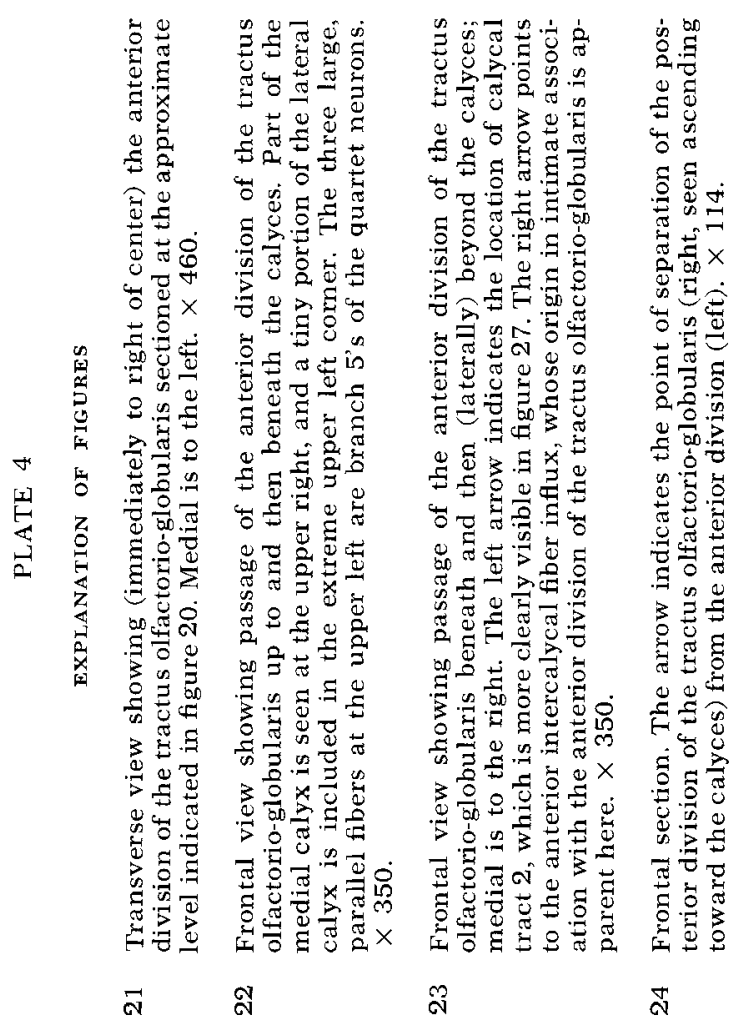



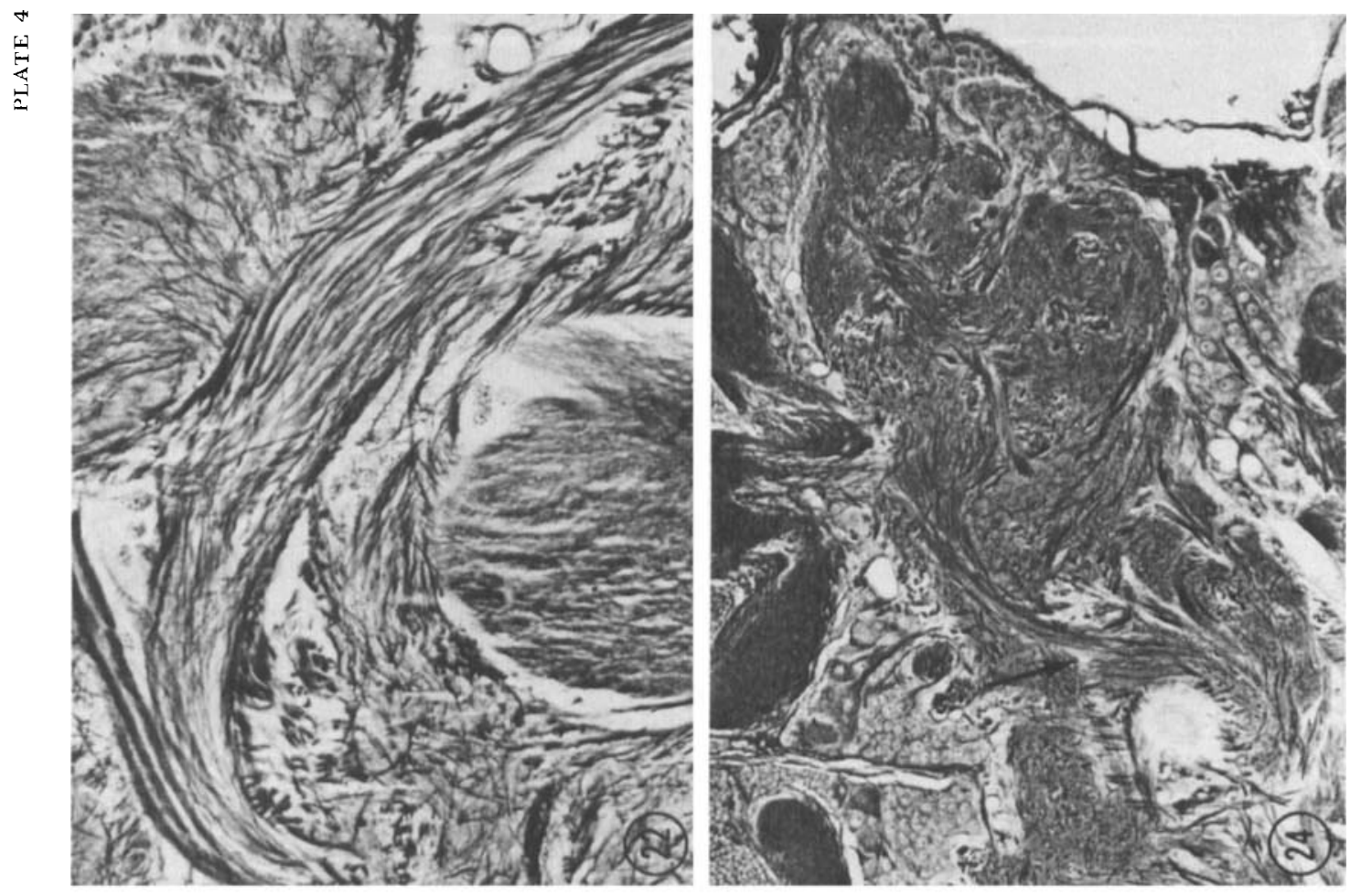

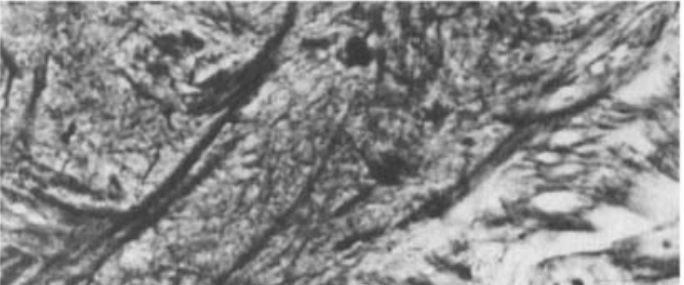

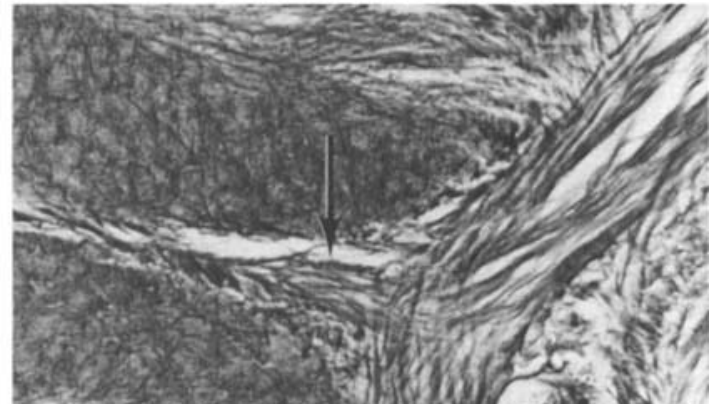

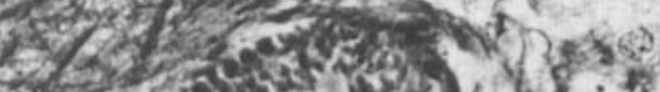

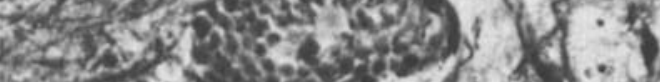

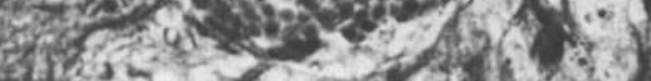

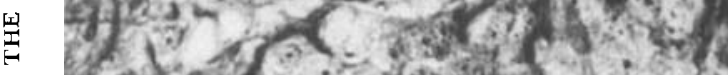

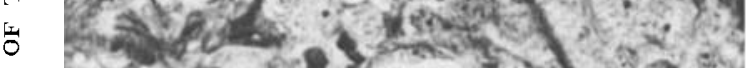

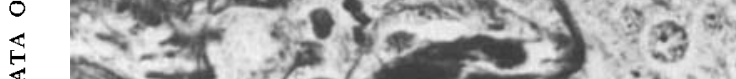

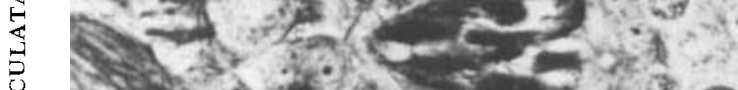

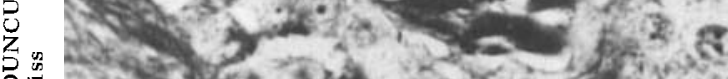

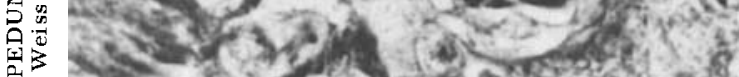

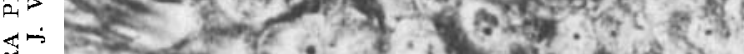

क्ष

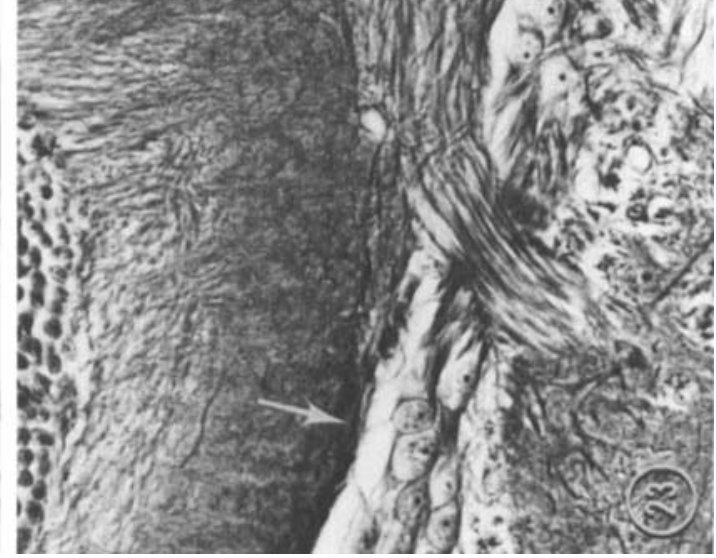




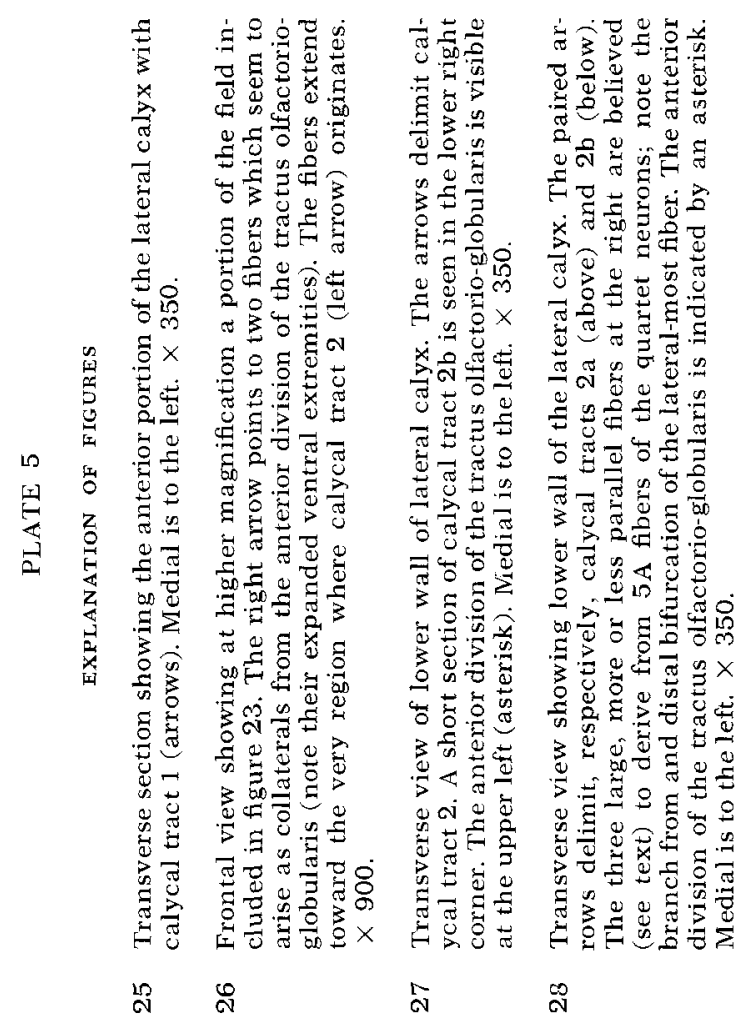



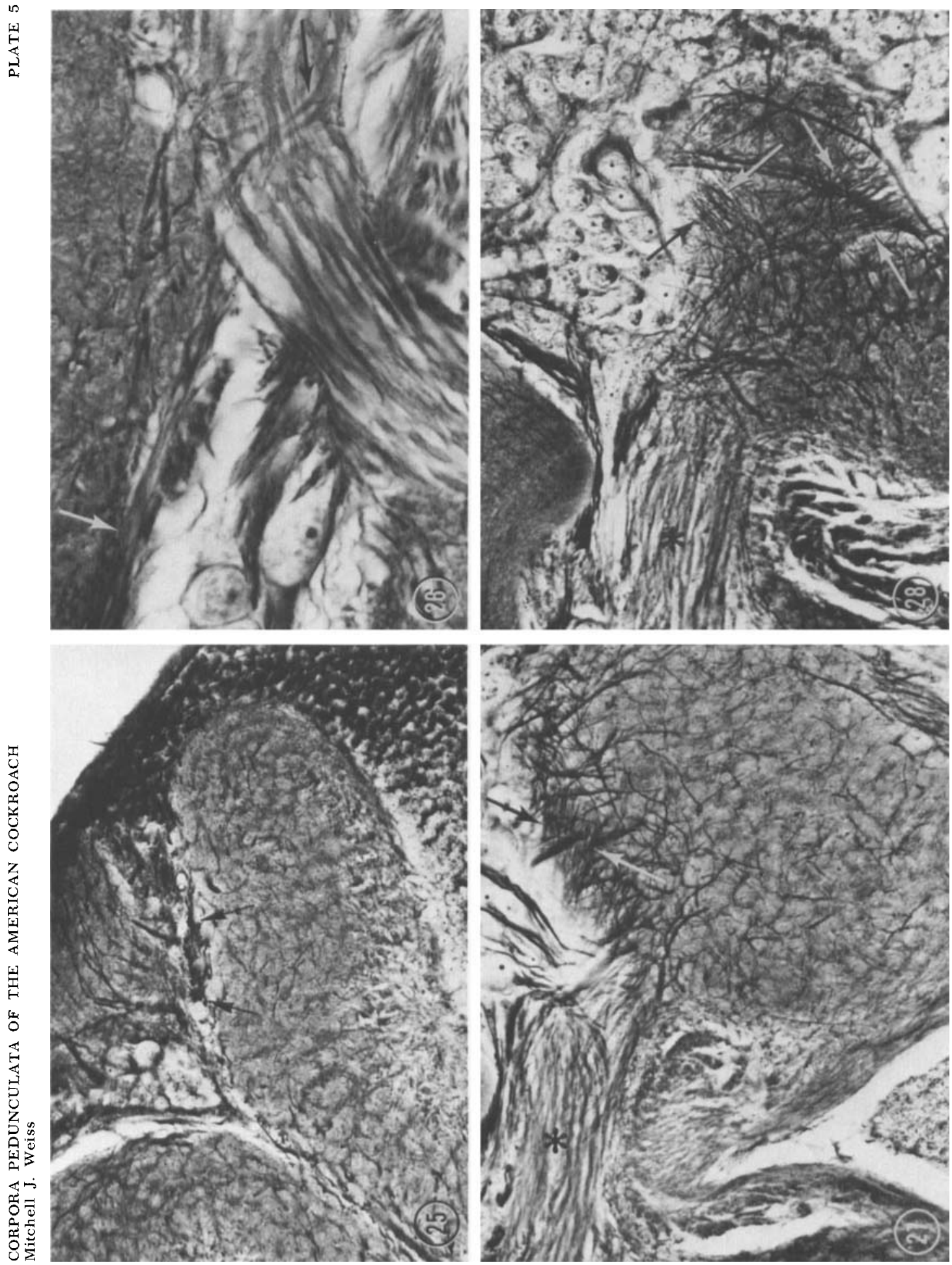
PLATE 6

EXPLANATION OF FIGURES

29 Transverse view of field comparable to part of that shown in figure 28 , but from the adjacent (more dorsal) section. Arrows delimit calycal tract $2 \mathrm{a}$. The anterior division of the tractus olfactorio-globularis is indicated by an asterisk. Medial is to the left. $\times 460$.

30 Transverse view of lower wall of lateral calyx, showing (just below center) the distal dispersion of calycal tract $2 \mathrm{~b}$. Medial is to the left. $\times 350$.

31 Frontal view of apposed calyces, sectioned posterior to the pedunculus. Medial is to the left. The paired arrows at the left delimit calycal tract 5 , while those further to the right delimit tract 4 . The single short arrow at the far right points to branch 7 's of the quartet neurons. $\times 350$.

32 Frontal view of field comparable to that shown in figure 31 but from a more posterior section through the same hemisphere. Medial is to the left. The arrows, from left to right, point respectively to calycal tract 5 , one of the branch 7's of the quartet neurons, and calycal tract 4 a (additional products of the splitting-up of tract 4 are seen just to the upper left of the branch 7's). $\times 460$. 
CORPORA PEDUNCULATA OF THE AMERICAN COCKROACH
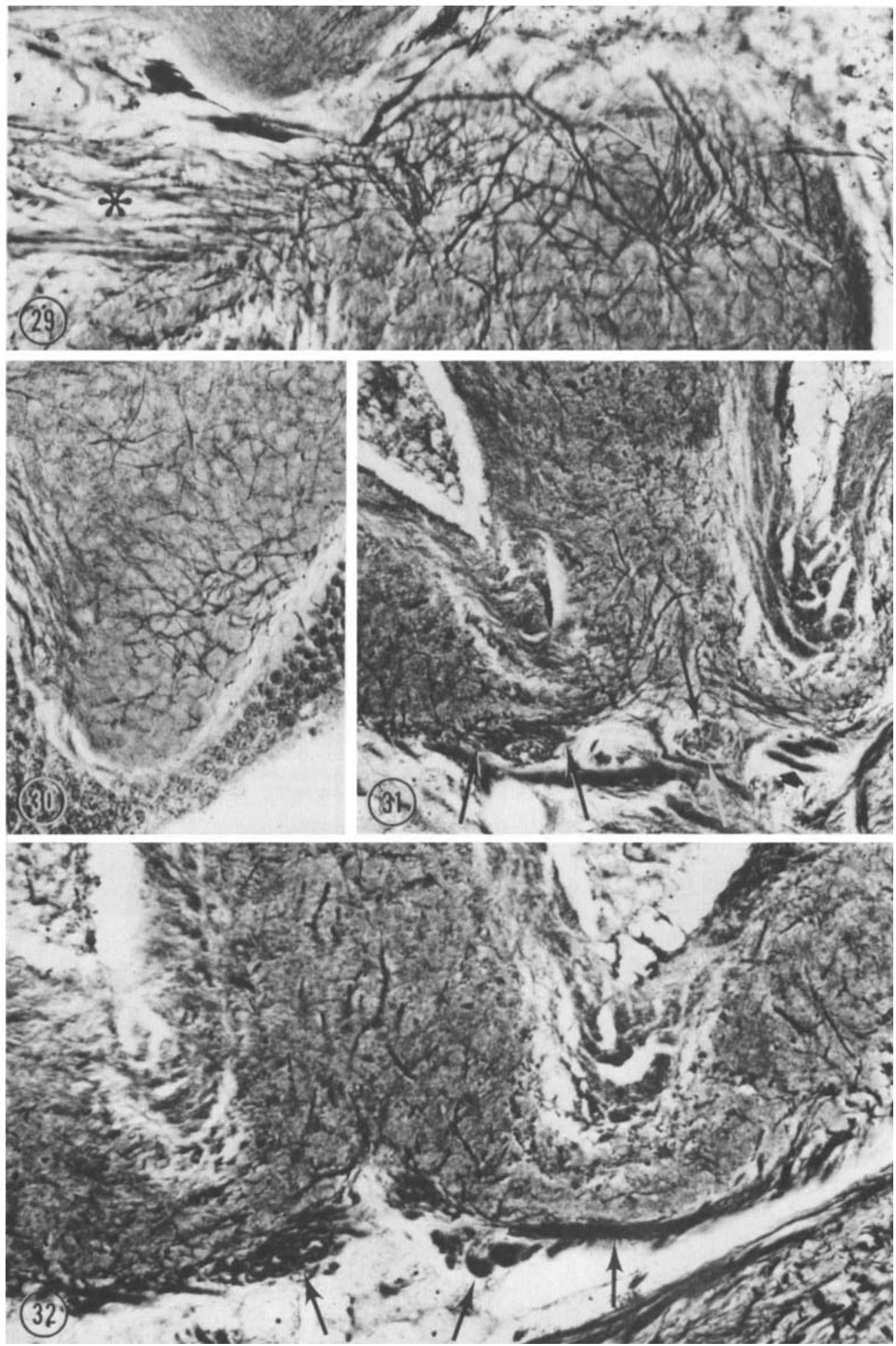


\section{PLATE 7}

EXPLANATION OF FIGUPES

33 Frontal view of lateral calyx, showing calycal tract 5 a (dark band at lower margin of calyx). Medial is to the left. $\times 450$.

34 Transverse view showing lower wall of lateral calyx, sectioned at a level at which calycal tract $2 a$, if present as such, should be visible laterally at the anterior margin of the zona externa (medial is here to the left). Note the presence there, however, of only scattered fibers, of which the larger ones are believed to derive from $5 \mathrm{~A}$ branches of the quartet neurons. Compare figure 29. The arrow points to the proximal section of calycal tract 2 . The anterior division of the tractus olfactorio-globularis is indicated by an asterisk. $\times 460$.

35 Transverse view showing lower wall of the lateral calyx. A section of the transversely oriented "extra" calycal tract described in the text is delimited by arrows. The anterior division of the tractus olfactorio-globularis is indicated by an asterisk. Medial is to the right. $\times 450$. 

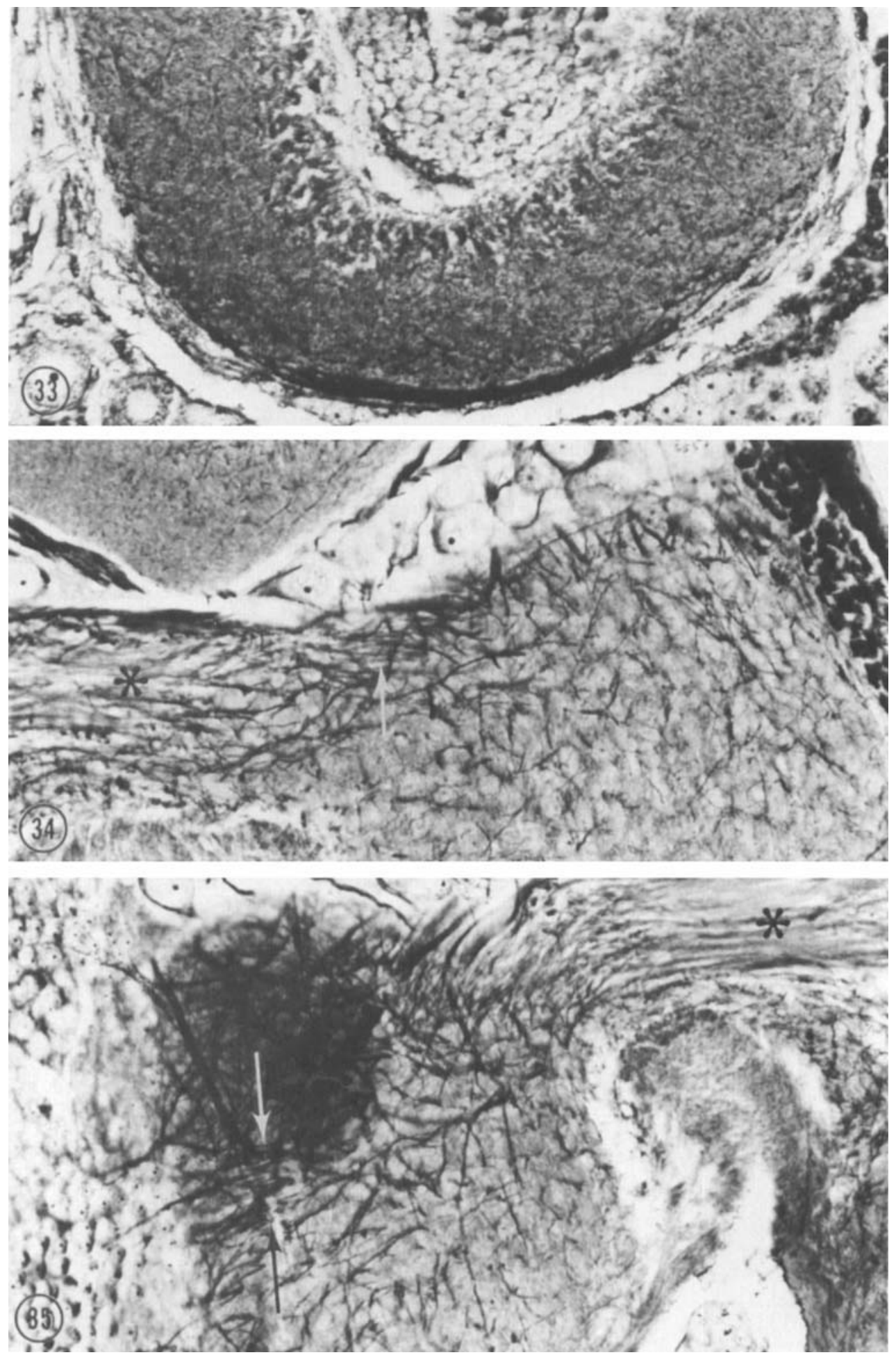


\section{PLATE 8}

\section{EXPLANATION OF FIGURES}

36 Transverse view of an anterior portion of medial calyx showing presence of a calycal tract (arrow) at the external margin of the zona externa. Medial is to the right. $\times 350$.

37 Frontal view of posterior section through the brain. The vertical fiber mass situated in the intercalycal region includes calycal tract $5 \mathrm{~b}$ as well as branches of the quartet neurons. The arrow points to fibers of the quartet neurons sectioned posterior to their entrance into the protocerebral neuropile. $\times 113$.

38 Periplaneta americana, adult male. Electron micrograph of frontal section through a portion of the anterior division of the tractus olfactorioglobularis; some synaptic neuropile of the zona externa of an adjacent calyx is visible at the upper edge of the picture (asterisks). The arrow, which is directed approximately dorsad, indicates a collateral process which arises perpendicularly from a fiber within the anterior division and which presumably is destined for one or another calycal tract. The micrograph is from material fixed in glutaraldehyde, post-fixed in osmic acid, embedded in Epon 812, and stained with Reynold's lead citrate. Approximately $\times 2700$. Inset: Frontal section through a portion of the anterior division of the tractus olfactorio-globularis (photomicrograph). The arrow indicates point at which a vertically oriented fiber seems to originate as a perpendicular collateral (compare electron micrograph). Medial is to the right. $\times 1570$. 

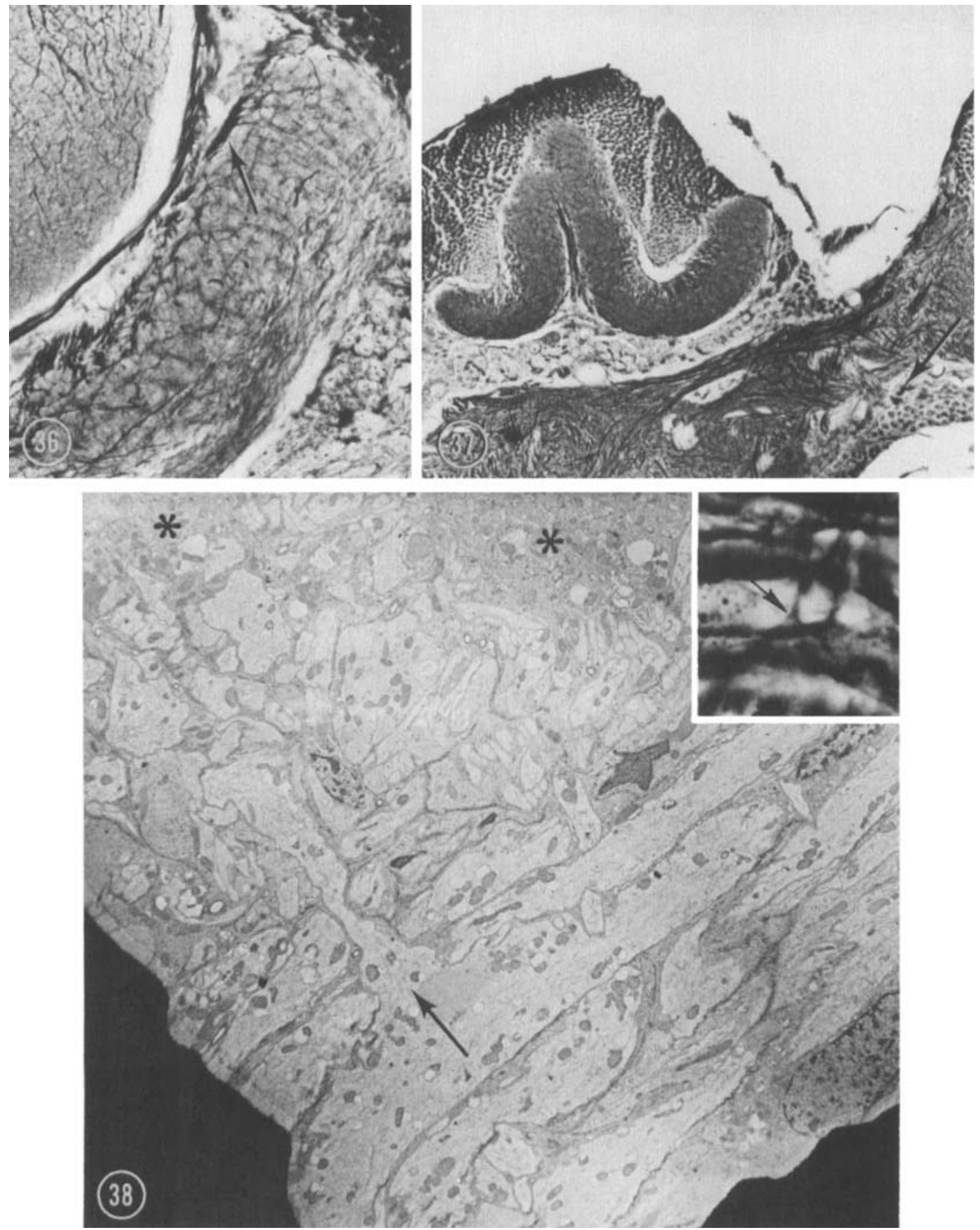


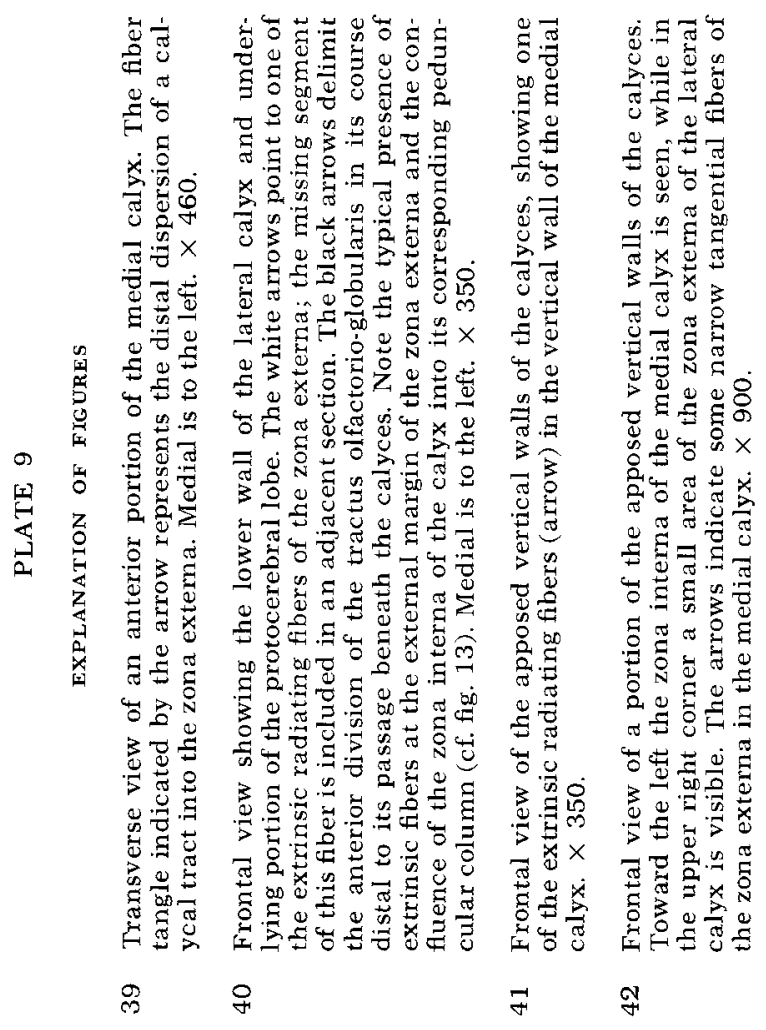


a
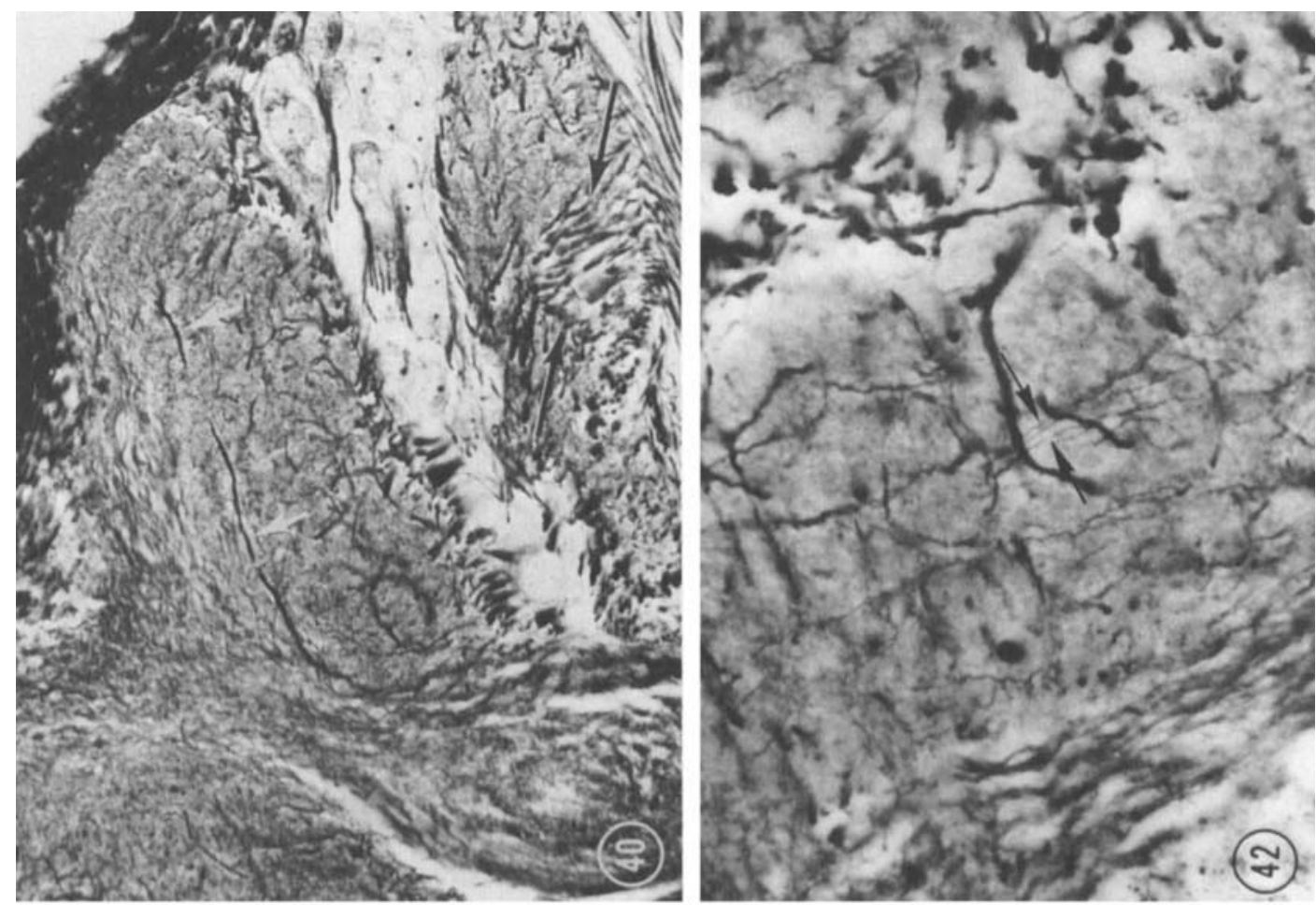

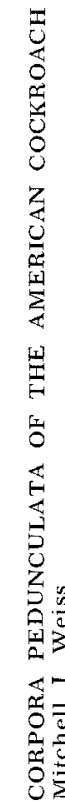
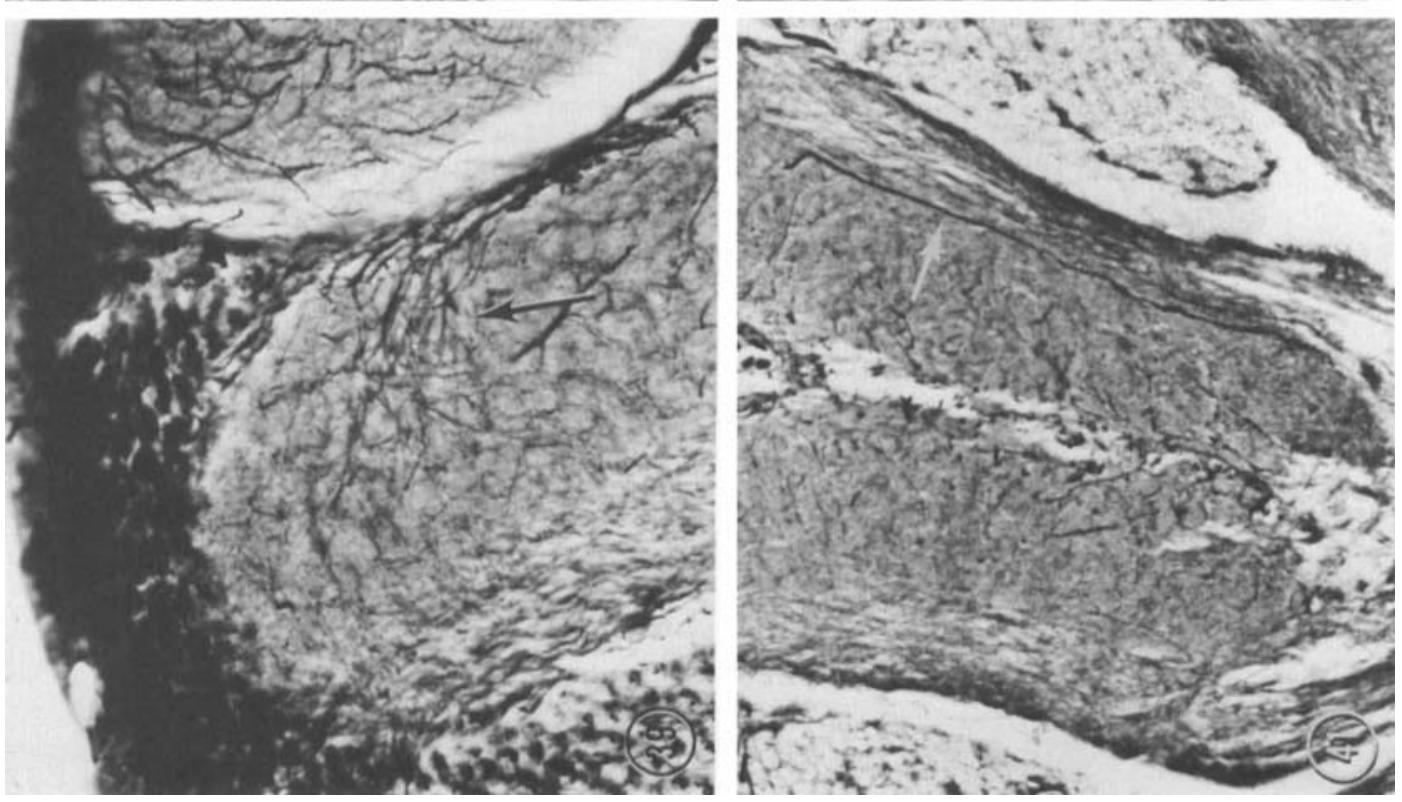
PLATE 10

EXPLANATION OF FIGURES

43 Frontal view of lower wall of the lateral calyx. Toward the upper right the zona interna is seen; toward the lower left the external margin of the zona externa is visible. The arrows indicate some narrow tangential fibers of the zona externa. Medial is to the right. $\times 900$.

44 Frontal view showing medial portion of the lower wall of the lateral calyx; medial is to the left. The curvature downward of the zona interna to form the peduncular column is seen at the upper and left borders of the picture. The arrow points to one of the narrow tangential fibers of the zona externa: note the direction of its course. $\times 900$.

45 Frontal view of a field within the lower wall of the lateral calyx comparable to that seen in the left half of figure 44 ; medial is to the left. The arrow points to a bundle of narrow tangential fibers of the zona externa in that portion of their course just proximal to their application onto the zona interna (above and left). $\times 900$.

46-47 Transverse sections through the same pedunculus, figure 47 representing the more ventral level. Medial is to the left. Black arrows delimit some points along the border (difficult to distinguish in these blackand-white photographs) between the lightly stained peripheral layer within the special posterior zone of the pedunculus and the surrounding neuropile. White arrows point to that portion of the underlying darkly stained layer which proximally extends forward between the two peduncular columns but distally becomes progressively excluded from this region. Both $\times 320$. 

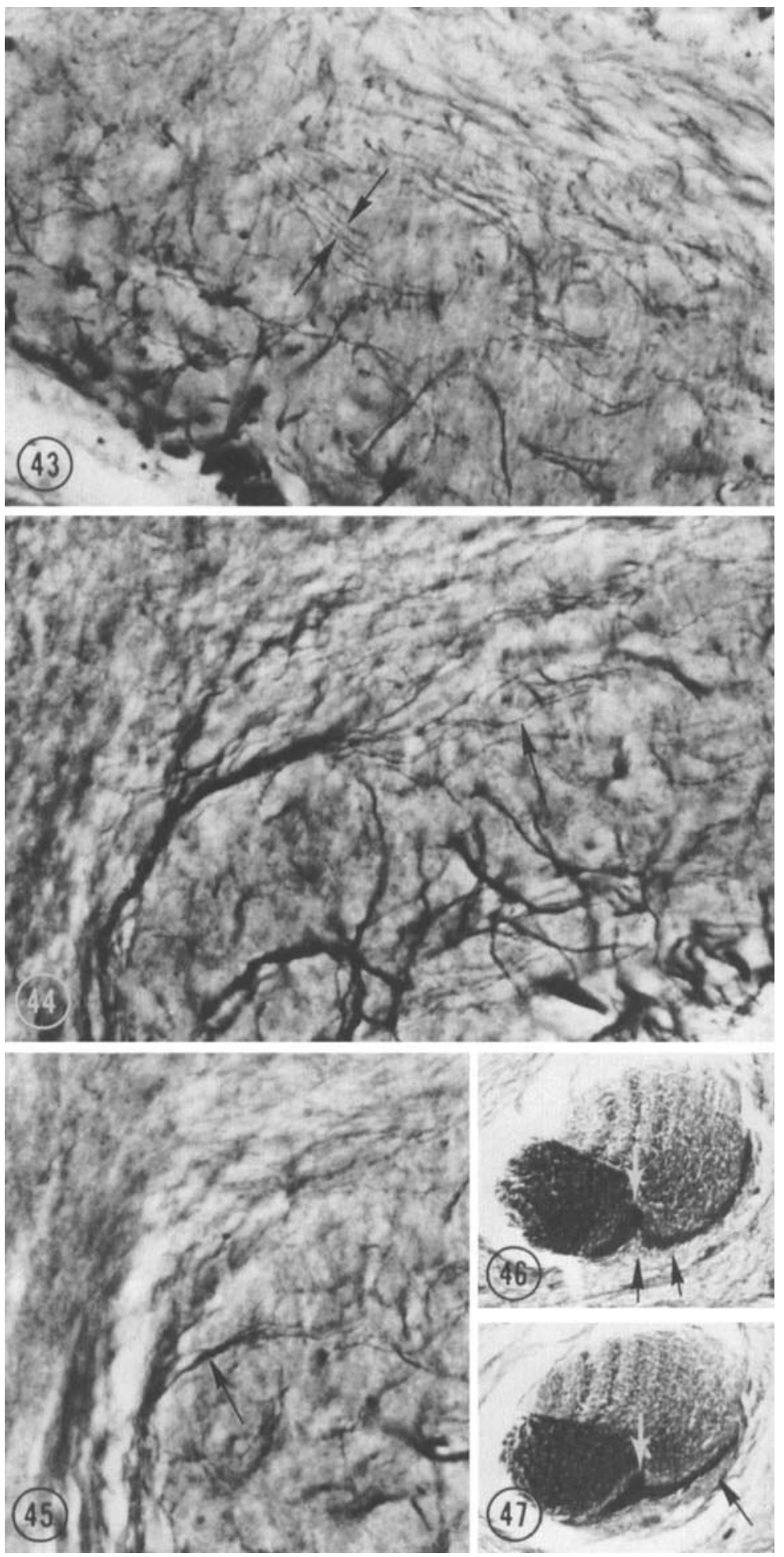
PLATE 11

EXPLANATION OF FIGURES

48 Frontal view showing rim of the lower wall of the medial calyx. Medial is to the right. The arrows point to two narrow tangential fibers of the zona externa seen extending up to its margin. Note the extension of the layer of globuli cell somata down along the external surface of the zona externa $($ right $) . \times 900$.

49 Frontal view showing the lower walls of the medial calyces on either side of the midline. On each side the layer of globuli cell somata can be seen to extend far along the external surface of the zona externa. The arrow points to a fiber bundle which extends out of the layer of somata onto this surface in the direction of the calycal rim. $\times 450$.

50 Frontal view showing the larger size of the most peripheral globuli cell somata of the calyces (arrow) in comparison with the remaining somata. Medial is to the right. Approximately $\times 280$.

51 Frontal view showing presence of short segments of nerve fibers (arrow) between the $\alpha$ lobe (left) and the adjacent surface of the medial caly $x$ (right). Medial is to the right. $\times 350$. 

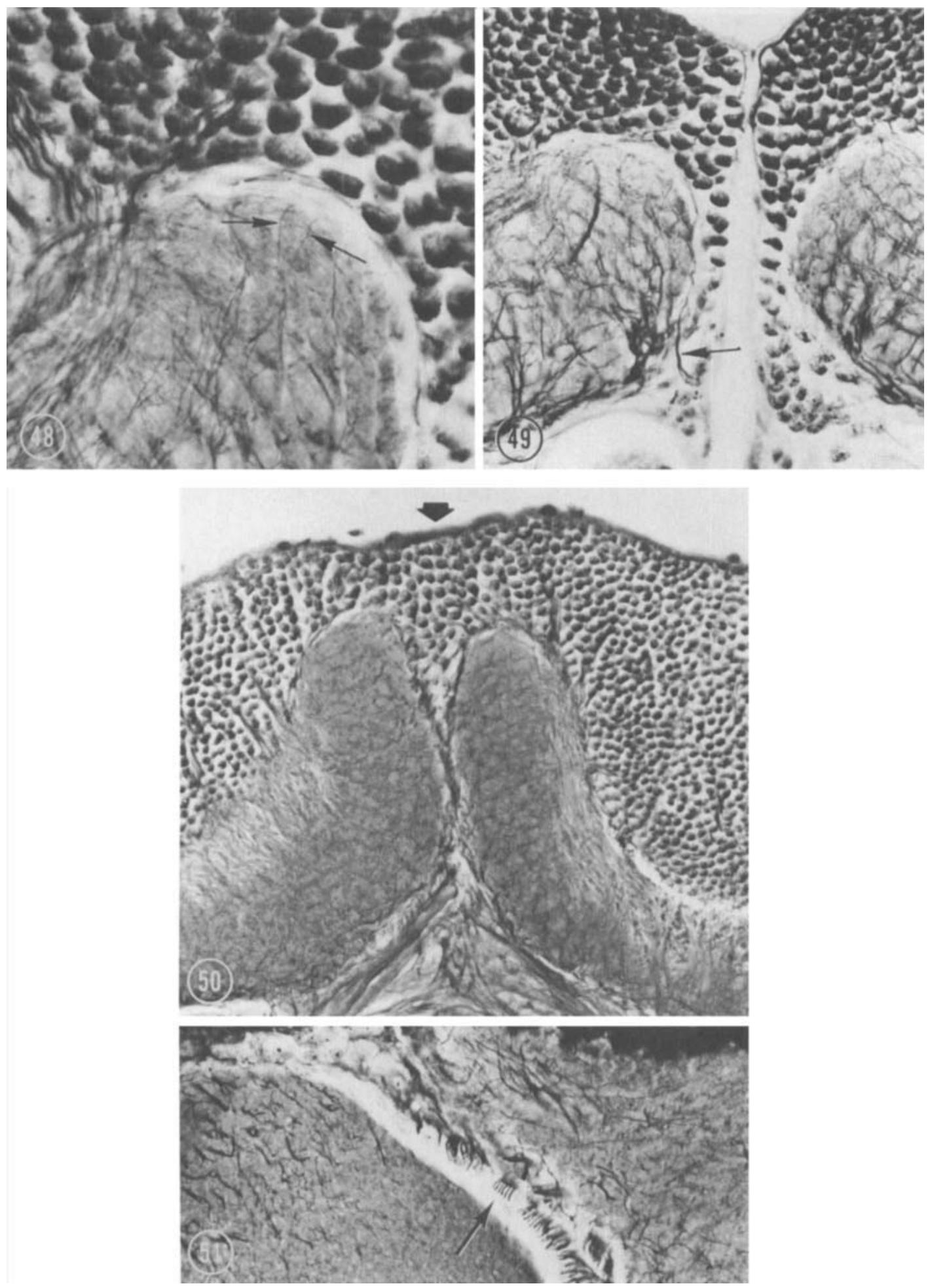